\title{
Review Article \\ Function of Nanocatalyst in Chemistry of Organic Compounds Revolution: An Overview
}

\author{
Kanagarajan Hemalatha, ${ }^{1}$ Gunabalan Madhumitha, ${ }^{1}$ Amir Kajbafvala, ${ }^{2}$ \\ Narayanan Anupama, ${ }^{1}$ Rajesh Sompalle, ${ }^{3}$ and Selvaraj Mohana Roopan ${ }^{3}$ \\ ${ }^{1}$ Organic Chemistry Division, School of Advanced Sciences, VIT University, Vellore, Tamil Nadu 632 014, India \\ ${ }^{2}$ Department of Materials Science and Engineering, North Carolina State University, Engineering Building I, Raleigh, \\ NC 27695-7907, USA \\ ${ }^{3}$ Chemistry Research Laboratory, Organic Chemistry Division, School of Advanced Sciences, VIT University, Vellore, \\ Tamil Nadu 632 014, India
}

Correspondence should be addressed to Selvaraj Mohana Roopan; mohanaroopan.s@vit.ac.in

Received 2 April 2013; Accepted 21 April 2013

Academic Editor: Minghang Li

Copyright (c) 2013 Kanagarajan Hemalatha et al. This is an open access article distributed under the Creative Commons Attribution License, which permits unrestricted use, distribution, and reproduction in any medium, provided the original work is properly cited.

\begin{abstract}
Heterocyclic motif is an important scaffold which has both industrial and pharmaceutical applications. These motifs can be prepared using wide variety of reaction conditions such as the use of expensive catalyst, toxic solvent, harsh reaction condition like the use of base, high temperature, and multistep reaction. Although various methods are involved, the chemistry arena is now shifted towards the greener way of synthesis. Nanocatalyst constitutes an important role in the green synthesis. This is because the activity of the catalyst resides in the exposed portion of the particles. By decreasing the size of the catalyst, advantages such as more surface area would be exposed to the reactant, only negligible amount would be required to give the significant result and selectivity could be achieved, thereby, eliminating the undesired products. The current review enlists the various types of nanocatalyst involved in the heterocyclic ring formation and also some other important functionalization over the ring.
\end{abstract}

\section{Introduction}

The new era of chemistry is shifting towards the path of innovative techniques which mainly concentrates on environmental aspects $[1,2]$. Each and every component of the reaction is investigated on the basis of ecofriendly concepts such as use of nonhazardous solvent (water) and solventfree synthesis or inexpensive catalyst, without affecting the yield and quality of the reaction. Synthesis of heterocyclic core constitutes the important portion of organic synthesis because it has wide variety of pharmacological actions [3-6]. Various methods have been adopted for the synthesis which includes the use of catalyst $[7,8]$, ultrasound irradiation [9-11], and microwave irradiation [12, 13]. Although these methods have their own advantages, it also possesses certain disadvantages like expensive instruments, inaccessible materials, nonrecyclable and non-selectivity, and so forth. To overcome these, the role of nanocatalyst holds its application [14]. Nanoscience is the cram of phenomenon on a nanometer range. Atoms are a few tenths of a nanometer in diameter, and molecules are typically a few nanometers in size. The smallest structures humans have been made have dimensions of a few nanometers and the smallest structures we will ever make will have the dimensions of a few nanometers. This is because as soon as a few atoms are placed next to each other, the resulting structure is a few nanometers in size. Chemistry is the study of molecules and their reactions with each other. Since molecules typically have dimensions of a few nanometers, almost all of nanoscience can be reduced to chemistry. Chemistry research in nanotechnology concerns carbon nanotubes, self-assembly, $\mathrm{C}_{60}$ molecules, and structures built using DNA. Sometimes the chemical description of a nanostructure is insufficient to describe its function. Owing to the hasty progress of nanoscience and nanotechnology, the primeval colloid science is given a new life. Because of their great differences from single molecules and bulk materials, nanoscale materials, including colloids, have attracted much attention since the last decade, especially 


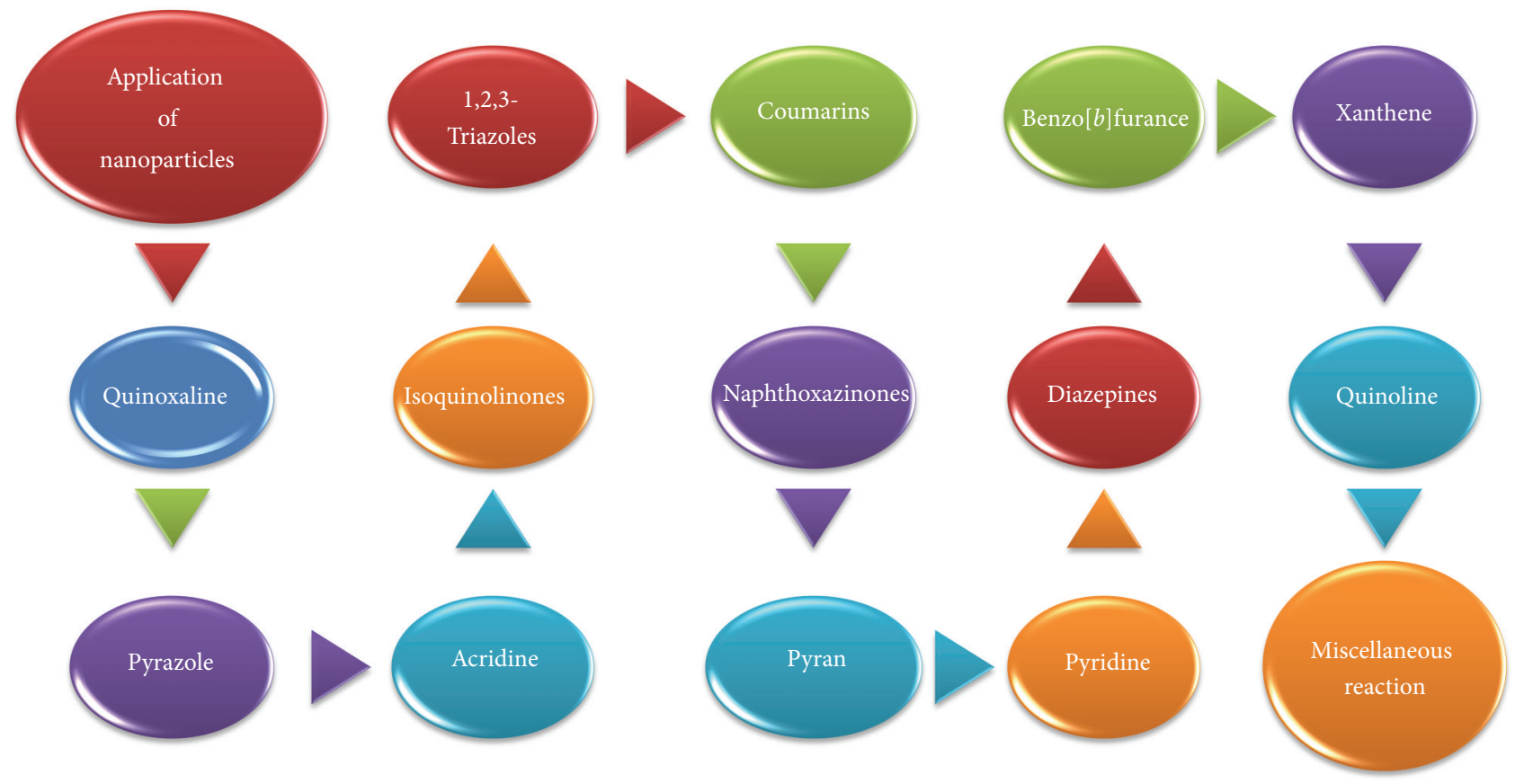

FIGURE 1: Application of nanoparticles in organic synthesis.

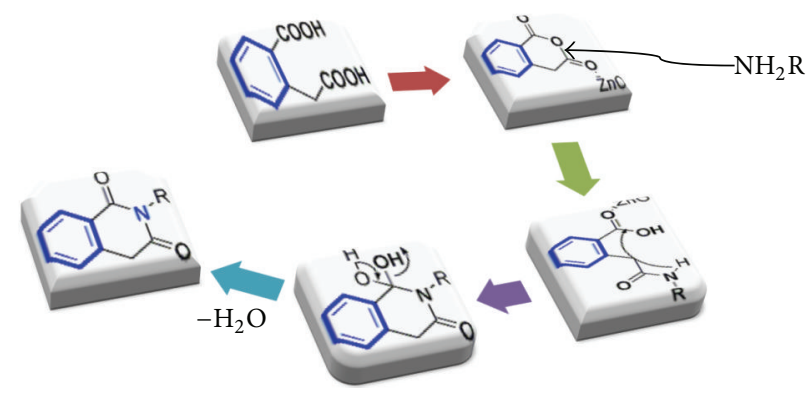

Figure 2: Possible mechanism for the formation of $N$-arylhomophthalimide, 2.4.2.<smiles>O=c1oc2ccccc2cc1-c1csc(NC2=NOC(c3ccccc3)C2)n1</smiles>

Anti-inflammatory

(a)<smiles>O=C1C(Cl)C(c2ccccc2)N1c1nc(-c2cc3ccccc3oc2=O)cs1</smiles>

Antiallergic

(b)<smiles>O=c1oc2ccccc2cc1-c1csc(/N=C/c2ccccc2)n1</smiles>

Anticoagulant

(c)<smiles>[R]C=NNC(=O)COc1ccc2c(C)cc(=O)oc2c1</smiles>

Antitumor

(d)

FIgUre 3: Pharmacological activities of coumarins. 


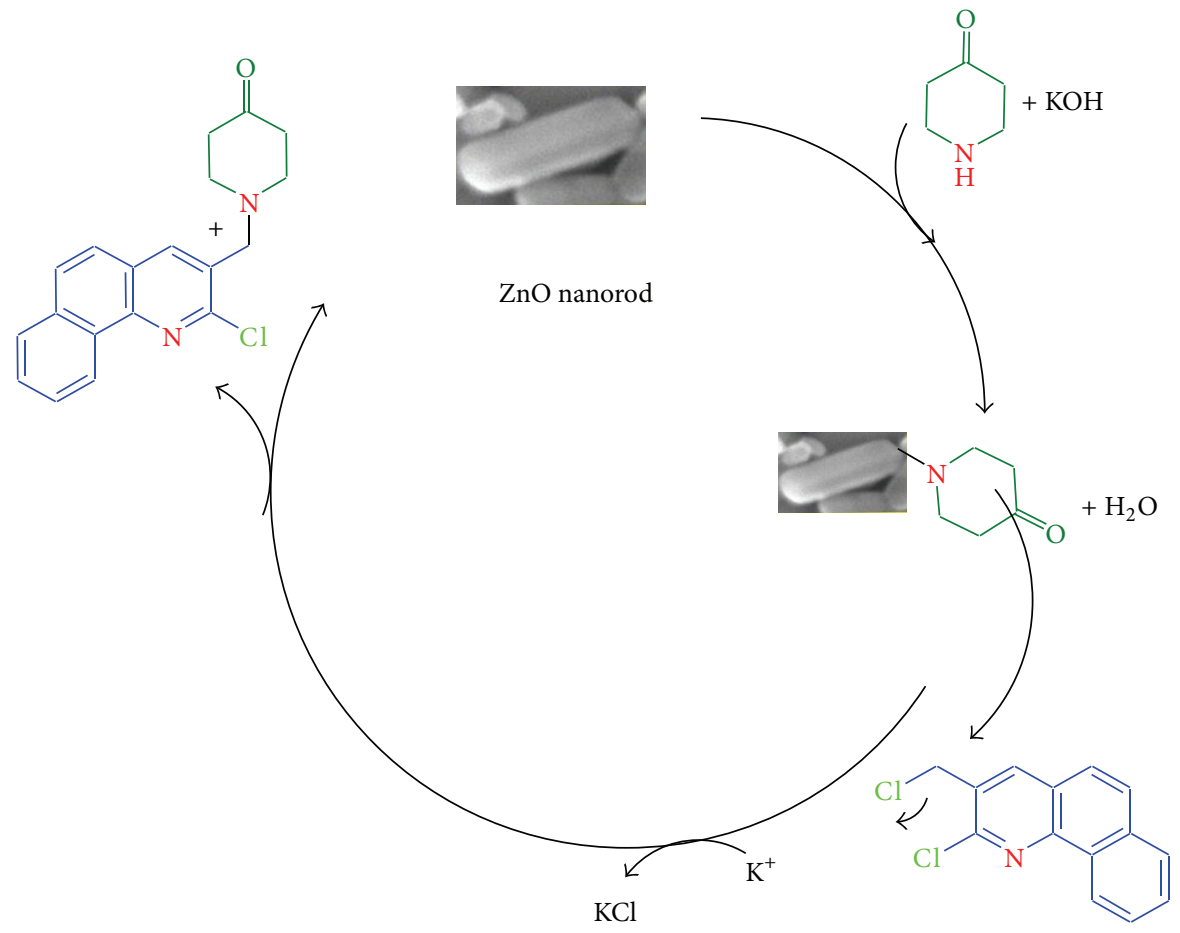

FIgURE 4: Role of $\mathrm{ZnO}$ nanorods in synthesis of $N$-alkylated products (adapted from [1]).

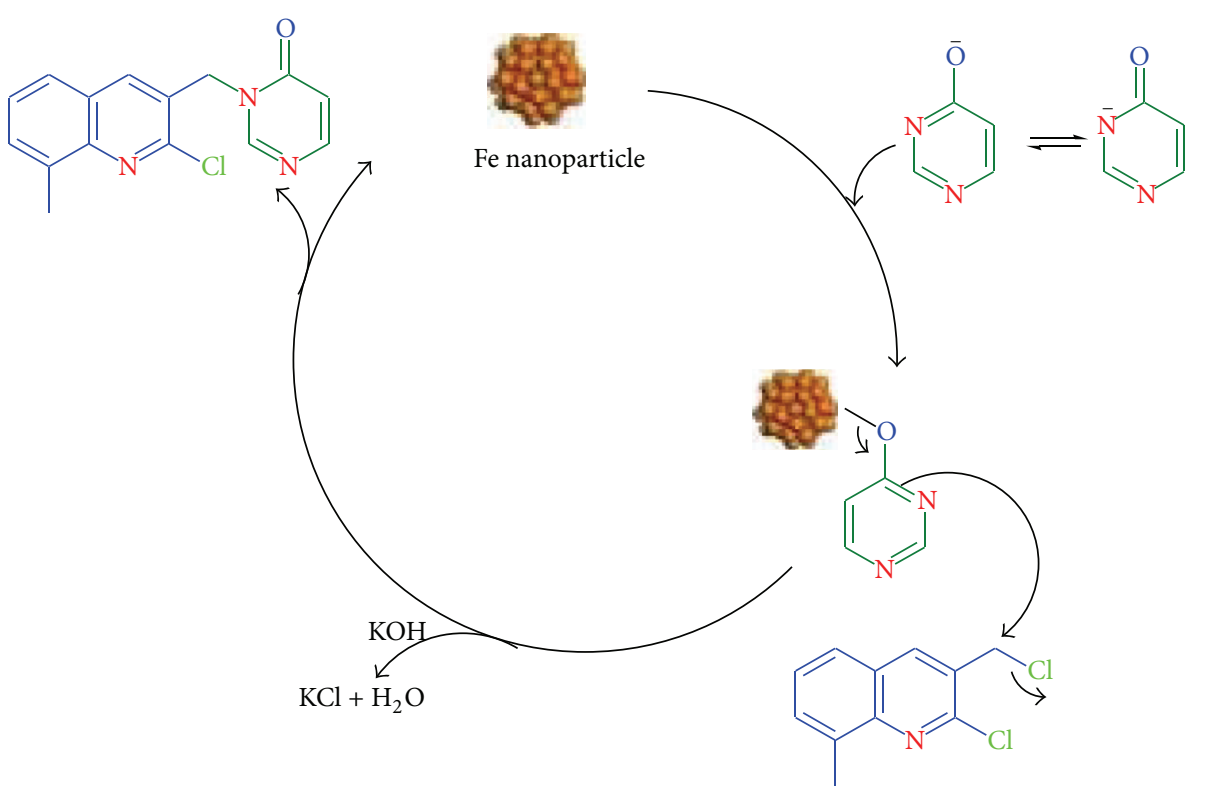

FIGURE 5: Role of Fe nanoparticles in $N$-alkylation reaction (adapted from [2]).

in the field of catalysis. Over the several past decades, catalysts and catalytic reactions have attracted considerable attention with the aim of finding meaningful applications in the pharmaceutical and fine chemical industries. The nanocatalysts are highly selective, reactive, and stable; thereby it supersedes the conventional catalyst. Nanoparticles with a diameter of less than $10 \mathrm{~nm}$ have generated intense interest over the past decade due to their high potential applications in areas such as sensors, nanoscale electronics, catalysis, and optics. The catalytic activity of nanoparticles is affected by size; therefore, the relative ratio of surface atom types changes dramatically with varying particle size. In many cases, the activity increases as the particle size decreases due to favorable changes in the electronic properties of surface atoms, which are located mainly on edges and corners in small particles. On the other hand, the reactivity and selectivity of metal nanocatalysts 
also depend strongly on the different crystallographic planes present on the nanoparticles and which can be achieved by controlling the morphology of these nanoparticles. Size and surface of the nanocatalyst play a major role because it is the reason for its selectivity and reactivity. Also, in some cases the enhancement by doping and surface chemical modifications would be done to increase its performance [15]. Nanocatalyst is not only used in organic transformation but also it has various applications $[16,17]$. These nanocatalysts can be prepared by various methods such as thermal decomposition, microarc oxidation irradiation, chemical vapor synthesis, nonsono and sonoelectrooxidation, sol-gel technique, chemical precipitation, photochemical method, hydrothermal method, antisolvent precipitation, glow discharge plasma electrolysis, wet-chemical method, microwave irradiation, and sonochemical method [16-21]. The size and nature of nanocatalyst varies on the type of method used for preparation [22-27]. Based on the requirement, the method of preparation can be selected. In this paper, we will review recent examples of nanoparticles used in organic transformation such as quinoxaline, naphthoxazinones, coumarins, 1,2,3-triazoles, acridine, pyrazole, and isoquinolinones. (Figure 1). The heart and soul of this paper is Section 2.23, where we cover miscellaneous functionalization on heterocycles; this is a challenge for nanocatalyst researchers to engage.

\section{Application of Nanoparticles in Organic Synthesis}

2.1. Synthesis of Quinoxaline Analogues. Quinoxaline is an important chemical entity which has interesting biological properties such as trypanocidal property [28], antimycobacterial agent [29], and cytotoxic agent [30]. The synthesis of quinoxalines (Scheme 1) was carried out by oxidative coupling of 1,2-diamines, 2.1.1 and 1,2-dicarbonyl compounds, 2.1.2 using gold nanoparticles supported on nanoparticulated ceria $(\mathrm{Au} / \mathrm{CeO})$ or hydrotalcite $(\mathrm{Au} / \mathrm{HT})$ as catalysts and air as an oxidant. The use of nanoparticles led to the mild reaction conditions such as base-free reactions, using mild temperature and air as an oxidant. The catalyst could be reused only with a little loss in activity [31]. The use of inexpensive and recyclable $\mathrm{SiO}_{2}$ which has highly reactive $-\mathrm{OH}$ group on its surface has its application in the synthesis of quinoxaline, and it produces high yield in less reaction time. Because of its reusable nature, it supersedes the other catalyst [32]. Quinoxalines can also be synthesized by advantageous nano- $-\mathrm{BF}_{3} \cdot \mathrm{SiO}_{2}$ and nano- $-\mathrm{TiO}_{2}$ catalyst systems. The reaction was carried out at varied temperatures and different moles of reactants to optimize the reaction condition and concluded that solvent-free conditions at room temperature could be the optimal one. In addition, the report concluded that the reaction time could be reduced by performing the reaction under sonication [33]. In nano- $\mathrm{TiO}_{2}$ system, the same authors carried out the synthesis in the presence of nano- $\mathrm{TiO}_{2}$ and compared with bulk $\mathrm{TiO}_{2}$ and other applied catalysts. The satisfactory results were obtained in solvent-free condition at room temperature using $12 \mathrm{~mol} \%$ as a catalyst [34]. Lü and coworkers synthesized quinoxalines using magnetic $\mathrm{Fe}_{3} \mathrm{O}_{4}$ nanoparticles. The result shows that the reaction could be performed well in water using $10 \% \mathrm{Fe}_{3} \mathrm{O}_{4}$ nanoparticles as catalyst at room temperature, and the catalyst can be recovered easily by using external magnet and reused with consistent activity [35]. Polyaniline/ $\mathrm{SiO}_{2}$ nanocomposite material was prepared and it was used as a catalyst for the synthesis of quinoxalines. They reported that $10 \%$ catalyst was found to be optimal for the reactant transformation, and the catalyst activity was found to be consistent even after three runs [36]. Another popular method to synthesize quinoxalines is by using $\mathrm{TiO}_{2}$ nanoparticles as a catalyst. The optimal protocol system was found out by using dichloroethane as an efficient solvent with $2.5 \mathrm{~mol} \%$ catalyst to give the highest yield. Also o-phenylenediamine with electron-withdrawing group gave the higher rates and yield than the electron-donating groups [37]. The quantitative yield of quinoxaline was obtained in 10 minutes by using acetonitrile solvent system, $10 \mathrm{~mol} \%$ of Ninanoparticles as catalyst at $25^{\circ} \mathrm{C}$ stirred under $\mathrm{N}_{2}$ atmosphere [38]. Bardajee and coworkers prepared SBA-15 supported on Pd (II) Schiff-base complex nanocatalyst for the synthesis of 2, 3-disubstituted quinoxalines derivatives [39].

\subsection{Synthesis of Pyrazole Analogues. Pyrazole is an important} novelty which has reported insecticidal [40], antimalarial [41], anti-inflammatory, and antimicrobial [42] activities. Khan and coworkers synthesized 1-(4,5-dihydropyrazol1-yl) isoquinolines, 2.2.3 from chalcones, 2.2.2 and 1hydrazinylisoquinoline, and 2.2.1 using iron-oxide nanoparticles and this method of synthesis eliminates the autooxidation of the desired pyrazolines to the corresponding pyrazoles (Scheme 2) [43]. $\left(\alpha-\mathrm{Fe}_{2} \mathrm{O}_{3}\right)$-MCM-41 catalysts is impregnated with $10 \%$ of iron oxide nanoparticles as a recoverable and reusable catalyst (Scheme 3 ) for the synthesis of pyrazolo [3,4-c] pyridine, 2.2.6 derivatives from 3,5dibenzylidenepiperidin-4-one, $\mathbf{2 . 2 . 4}$ and hydrazine derivatives, 2.2.5a-c. The optimum amount of catalyst was found to be $0.015 \mathrm{~g}$, and further increase in the amount of catalyst has no effect on rate of the reaction and yield. Even though pure MCM-41, amino-functionalized MCM-41, and $\mathrm{Fe}_{3} \mathrm{O}_{4}$ produced satisfactory result, the ease of recoverability and reusability of $\left(\alpha-\mathrm{Fe}_{2} \mathrm{O}_{3}\right)$-MCM-41 made it to prefer this catalyst for the pyrazole analogue synthesis [44].

2.3. Synthesis of Acridine Analogues. Acridine, one of the important nitrogen heterocycle, shows activity such as antiherpes [45], antimalarial and antitumor [46], and larvicidal action [47]. Roopan and Khan performed an ecofriendly synthesis of 9-chloro-6, 13-dihydro-7-phenyl-5H-indolo [3, 2-c]-acridines, 2.3.3 by Friedlander condensation (Scheme 4) of 2-amino-5-chlorobenzophenone, 2.3.1 and 3,4-dihydro$2 \mathrm{Hcarbazol}-1(9 \mathrm{H})$-one, and 2.3.2 in the presence and absence of $\mathrm{SnO}_{2}$ nanoparticles under microwave irradiation. The reaction was not initiated in the absence of catalyst [48]. A comparative study of various nanoparticles $\left(\mathrm{Mn}_{3} \mathrm{O}_{4}, \mathrm{CuO}\right.$, $\mathrm{CaO}, \mathrm{MgO}$, and $\mathrm{Fe}_{3} \mathrm{O}_{4}$ ), optimization of solvent, and temperature showed that nano- $\mathrm{Fe}_{3} \mathrm{O}_{4}(10 \mathrm{~mol} \%)+$ solventfree conditions $+120^{\circ} \mathrm{C}$ as an efficient protocol for the synthesis (Scheme 5) of 1,8-dioxo-decahydroacridines, 2.3.6, from aldehyde, 2.3.5, dimedone, 2.3.4, and aromatic amine 


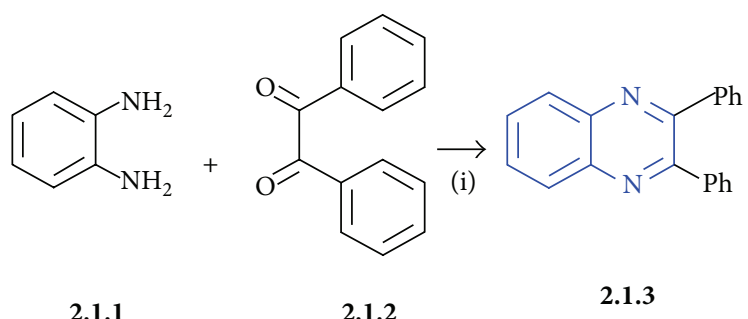

(i) $\mathrm{Au}, \mathrm{SiO}_{2}, \mathrm{BF}_{3}-\mathrm{SiO}_{2}, \mathrm{Fe}_{3} \mathrm{O}_{4}$, polyaniline $/ \mathrm{SiO}_{2}, \mathrm{TiO}_{2}, \mathrm{Ni}$, Pd/SBA-15

SCHEme 1: Synthesis of quinoxaline analogues, 2.1.3.

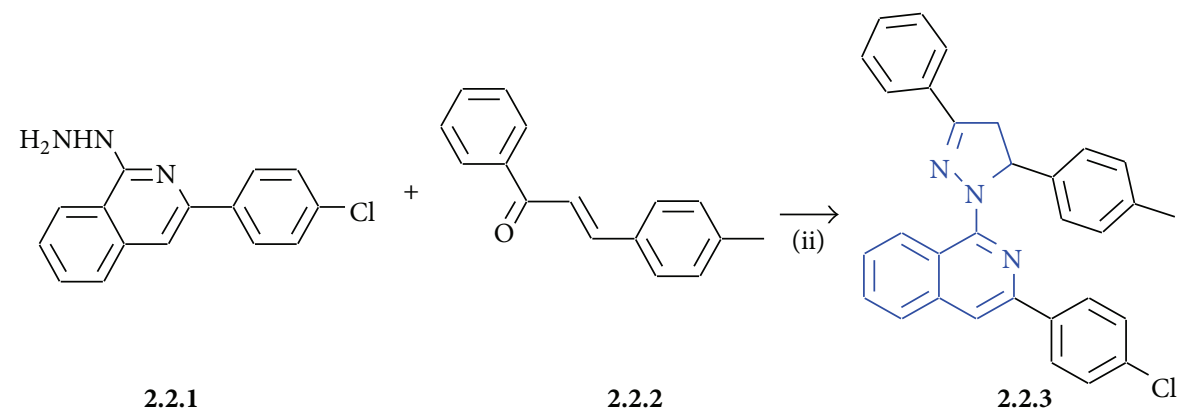

(ii) Iron oxide, ethanol, 30 min, reflux

Scheme 2: Synthesis of pyrazole analogues, 2.2.3.

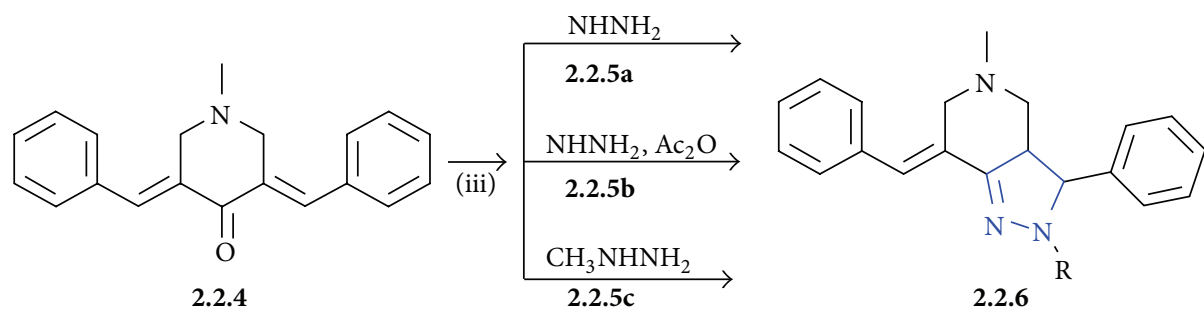

(iii) $\left(\alpha-\mathrm{Fe}_{2} \mathrm{O}_{3}\right)-\mathrm{MCM}-41-\mathrm{SO}_{3} \mathrm{H}$, ethanol, $30 \mathrm{~min}$, rt

Scheme 3: Synthesis of pyrazole analogues, 2.2.6 using dibenzylidenepiperidin-4-one.<smiles>Nc1ccc(Cl)cc1C(=O)c1ccccc1</smiles>

2.3.1<smiles>O=C1CCCc2c1[nH]c1ccccc21</smiles>

2.3.2<smiles>Clc1ccc2nc3c(c(-c4ccccc4)c2c1)CCc1c-3[nH]c2ccccc12</smiles>

(iv) $\mathrm{SnO}_{2}$ nanoparticles, $\mathrm{H}_{2} \mathrm{SO}_{4}, 500 \mathrm{~W}, \mathrm{MW}$

Scheme 4: Synthesis of acridine analogues, 2.3.3 using 2-amino-5-chlorobenzophenone. 


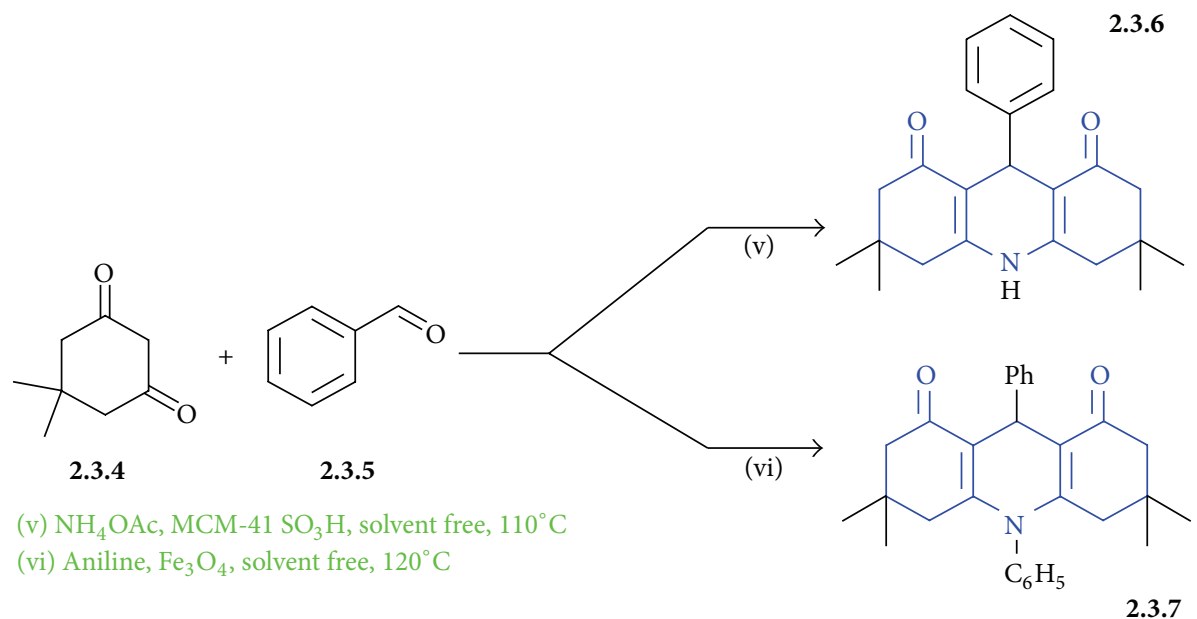

SCHEME 5: Multicomponent strategy to synthesis acridine analogues, 2.3.6-2.3.7.

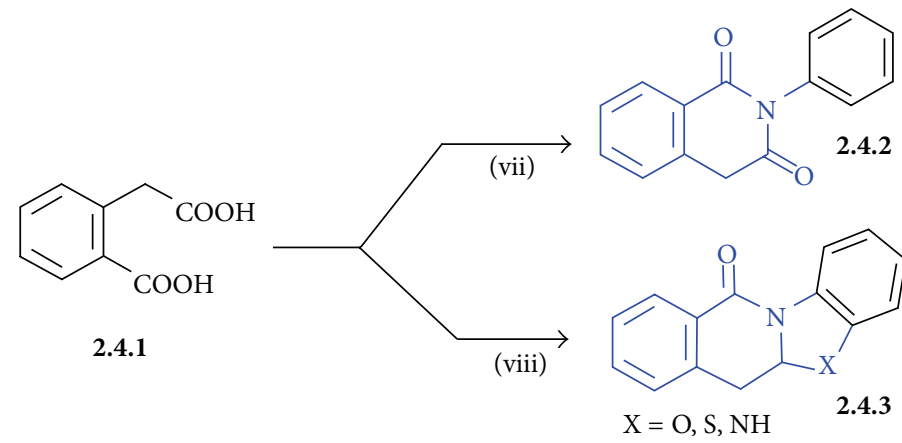

(vii) Aniline, $\mathrm{ZnO}$ nanoparticles, toluene, reflux

(viii) $\mathrm{C}_{6} \mathrm{H}_{4} \mathrm{NH}_{2} \mathrm{NH}_{2}$ (or) $\mathrm{NH}_{2} \mathrm{C}_{6} \mathrm{H}_{4} \mathrm{OH}$ (or) $\mathrm{NH}_{2} \mathrm{C}_{6} \mathrm{H}_{4} \mathrm{SH}$, $\mathrm{ZnO}$ nanoparticles, toluene, reflux

SCHeme 6: Synthesis of $N$-arylhomophthalimides, 2.4.4 and Isoquinolinones, 2.4.5.

in the presence of ammonium acetate [49]. $0.005 \mathrm{~g}$ of MCM$41-\mathrm{SO}_{3} \mathrm{H}, 110^{\circ} \mathrm{C}$ and solvent-free condition is another effective combination for obtaining 1,8-dioxo-9-aryl decahydroacridines nucleus, 2.3.7 [50].

\subsection{Synthesis of N-Arylhomophthalimides and Benzannelated} Isoquinolinones. Isoquinolinones are reported to cause allosteric modulation of metabotropic glutamate receptor 2 [51], and also it has JNK inhibitory action [52]. An emerald procedure was developed utilizing an efficient catalyst; that is, $\mathrm{ZnO}$ nanoparticles mediated the synthesis of $\mathrm{N}$ arylhomophthalimides and benzannelated isoquinolinones. Krishnakumar and coworkers synthesized flower-shaped $\mathrm{ZnO}$ nanoparticles and used them in the reaction between homophthalic acid, 2.4.1, and substituted anilines, benzyl amine, for the ecofriendly synthesis of $N$-arylhomophthalimide 2.4.2, and benzannelated isoquinolinones, 2.4.3 (Scheme 6). They carried out the reaction using various catalysts, solvents, and different concentration of the catalyst. $\mathrm{Nano} \mathrm{ZnO}$ at a concentration of $5 \% \mathrm{~mol}$ in the toluene system was found to be effective [53]. The $\mathrm{ZnO}$ nanoparticles exhibit admirable catalytic action, and the proposed methodology was capable of providing the desired products in good yield and purity. The possible mechanism for the formation of this product is illustrated in Figure 2.

2.5. Synthesis of 1,4-Disubstituted 1,2,3-Triazoles. 1,2,3triazoles (Scheme 7), an important entity, has reported antimycobacterial activity [54], anti-HSV-1 activity [55], and antifungal activity [56]. This moiety can be synthesized by an innovative concept called "click chemistry." It is a reaction between sodium azide, 2.5.1, and alkyne to give 1,4-disubstituted 1,2,3-triazoles in the presence of copper and water. This reaction is also known as $\mathrm{Cu}$-catalyzed alkyne azide cycloaddition. Since copper acts as a catalyst in the synthesis of triazoles, copper supported on various materials can be made into nanoparticles, and its yield and specificity can be increased further. Alonso and coworkers synthesized 1,2,3-triazoles through various heterocycles derived from natural product such as (-)-menthol, lactic acid, D-glucose, oestrone, and cholesterol converting them into alkynes by introducing propargyl groups. Propargyl methyl ether, 


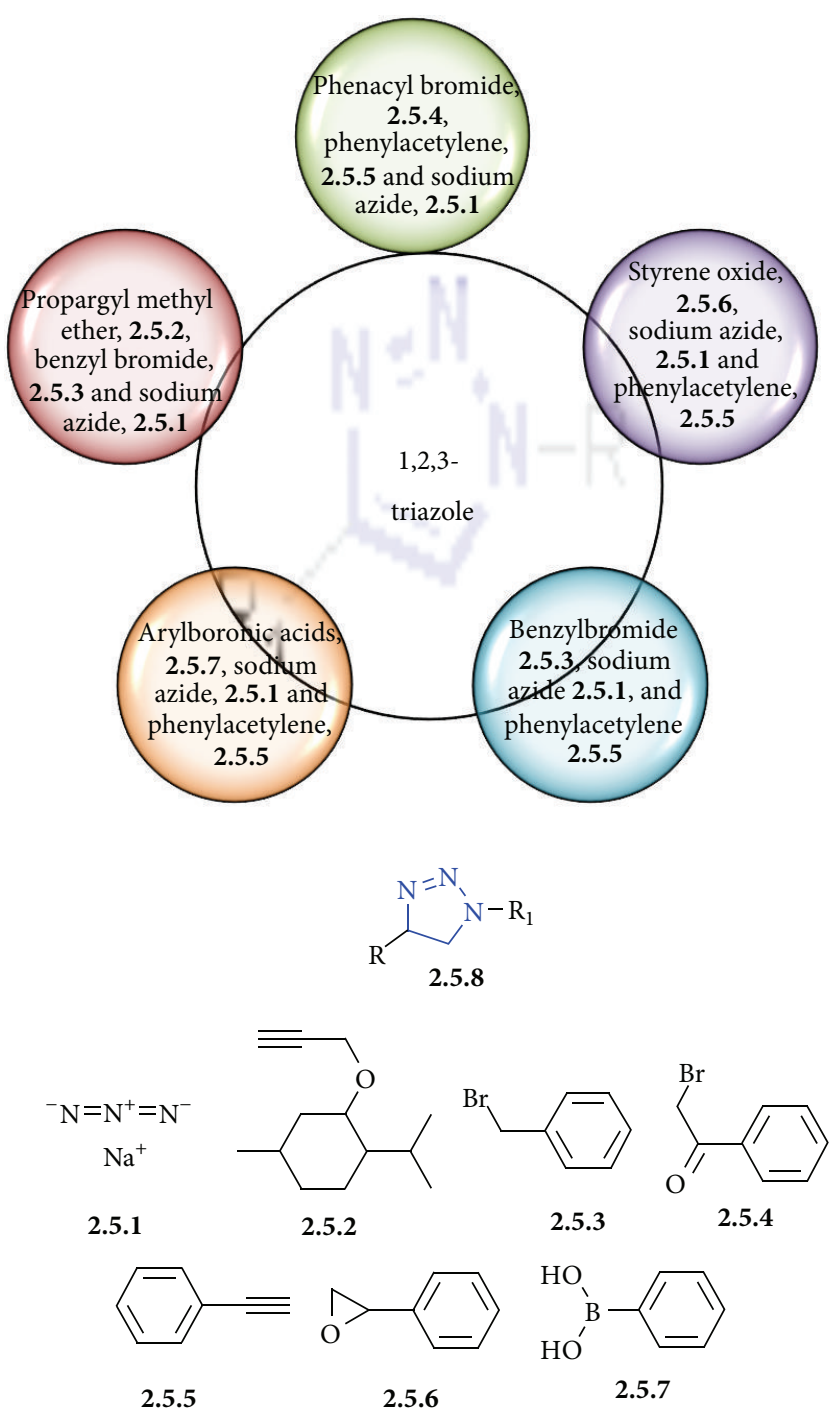

SCHEME 7: Synthesis of 1,2,3-triazoles, 2.5.8 using various strategy.<smiles>[R1]CC(=O)O</smiles><smiles>[R3]c1cc2cc([R3])c(=O)oc2c([R16])c1[R2]#N</smiles>

(ix) $\mathrm{ZnO}$ nanoparticles, $\mathrm{MW}$

$\mathrm{R}_{1}=\mathrm{H}, \mathrm{OH}, \mathrm{OMe}$

$\mathrm{R}_{3}=\mathrm{H}, \mathrm{Cl}, \mathrm{Br}, \mathrm{NO}_{2}, \mathrm{OH}$

$\mathrm{R}_{2}=\mathrm{H}, \mathrm{OH}, \mathrm{OMe}, \mathrm{Et}_{2} \mathrm{~N}$

$\mathrm{R}_{4}=\mathrm{CO}_{2} \mathrm{Et}, \mathrm{COMe}, \mathrm{CN}$

Scheme 8: Synthesis of coumarins, 2.6.3.

2.5.2, benzyl bromide, 2.5.3, and sodium azide, 2.5.1, under click reaction condition to give triazole derivatives. These derivatives of natural products having wide variety of application were obtained in high yield using copper nanoparticles [57]. CuI supported on poly(4-vinylpyridine) $\left[\mathrm{P}_{4} \mathrm{VPy}-\mathrm{CuI}\right]$ acts as a heterogenous catalyst for the synthesis of triazoles. Using the optimized ratio of $1: 1: 1.1$ of phenacyl bromide, 2.5.4, phenyl acetylene, 2.5.5 and sodium azide, 2.5.1, $0.1 \mathrm{~g}$ of $\mathrm{P}_{4} \mathrm{VPy}-\mathrm{CuI}$ and water, required triazoles were obtained after refluxing. Also, this catalyst can be reused up to 8 runs without losing its efficiency [58]. Metalloanthraquinone complex, an important catalyst for the synthesis of 1,4-disubstituted 1,2,3-triazole, was prepared, and various reaction conditions were studied. Various metal 


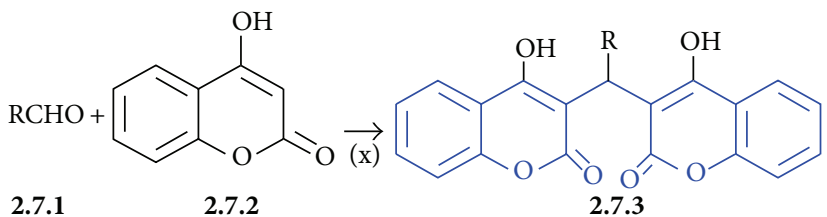

(x) PVP-Ni, ethylene glycol, $\mathrm{rt}$

$\mathrm{R}=4-\mathrm{ClC}_{6} \mathrm{H}_{4}, 4-\mathrm{NO}_{2} \mathrm{C}_{6} \mathrm{H}_{4}, 4$ and 2- $\mathrm{OHC}_{6} \mathrm{H}_{4}, 3,4\left(\mathrm{CH}_{3} \mathrm{O}\right)_{2} \mathrm{C}_{6} \mathrm{H}_{3}$, piperonyl

Scheme 9: Synthesis of biscoumarins, 2.7.3.<smiles>O=Cc1ccccc1</smiles>

2.8.1<smiles>NC([NH3+])=O</smiles>

2.8.2<smiles>Oc1ccc2ccccc2c1</smiles>

2.8.3<smiles>O=C1NC(c2ccccc2)c2c(ccc3ccccc23)O1</smiles>

2.8.4

(xi) $\mathrm{Cu}$ nanoparticles, $\mathrm{K}_{2} \mathrm{CO}_{3}$, PEG-400

Scheme 10: Synthesis of naphthoxazinones, 2.8.4.

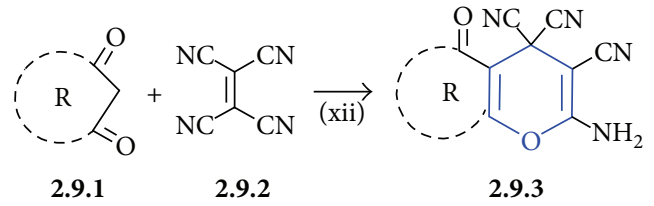

$\mathrm{R}=$ Alicyclic/heterocyclic (xii) $\mathrm{TiO}_{2} \mathrm{NPs}_{3} \mathrm{H}_{2} \mathrm{O}$, RT

SCHEme 11: Synthesis of pyran analogues, 2.9.3.<smiles>CC1(C)CC(=O)C2=C(C1)OC(N)=C(C#N)C2[Al]</smiles><smiles>[GeH3]</smiles>
$\mathrm{Ph}-\mathrm{CHO}$ 2.9.4<smiles>N#CC=CC#N</smiles><smiles>CCCC</smiles>
2.9.11<smiles>[Mg][Mg]</smiles>
$\mathrm{EtOOC} \widehat{\mathrm{COCH}_{3}}$ 2.9.8<smiles>N#CC1=C(N)Oc2c(c(=O)oc3ccccc23)C1[Al]</smiles><smiles>CCOC(=O)C1=C(C)OC(N)=C(C#N)C1[Al]</smiles>

2.9.9

(xv) Dimethylcyclohexane-1,3-dione, 2.9.6, $\mathrm{Fe}_{2} \mathrm{O}_{3}$

(xvi) $\mathrm{ZnO}$ nanoparticles (xiii) 4-Hydroxy-2H-chromen-2-one, 2.9.7 CuO

(xiv) 4-Hydroxy-2 $\mathrm{H}$-chromen-2-one, 2.9.7 $\mathrm{Fe}_{2} \mathrm{O}_{3}$

SCHEME 12: Multicomponent reaction for the construction of pyran analogues, 2.9.9-2.9.11. 
<smiles>CN1CC(=Cc2ccccc2)C(=O)C(=Cc2ccccc2)C(=Cc2ccccc2)C(=Cc2ccccc2)C1</smiles>

(xvii) $\mathrm{MCM}-41-\mathrm{SO}_{3} \mathrm{H}$, solvent free

Scheme 13: Synthesis of pyrano pyridine, 2.9.13.<smiles>O=Cc1cn(-c2ccccc2)nc1-c1ccc(Cl)cc1</smiles>

2.10 .1<smiles>COC(=O)CC(=O)OC</smiles>

$+$ $\mathrm{AcONH}_{4}$

2.10 .3<smiles>CCOC(C)=C1C(C)=C(C)NC(C)=C1C(=O)OC</smiles>

(xviii) $\mathrm{MgO}$ nanotube, $\mathrm{CH}_{3} \mathrm{CN}$, reflux

Scheme 14: Synthesis of 1,4-dihydropyridine derivatives, 2.10.4.

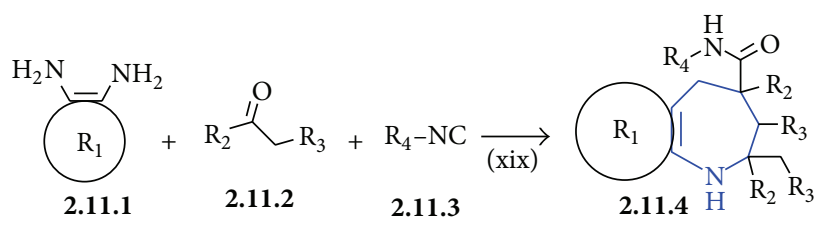

$\mathrm{R}_{1}=\mathrm{CN}, \mathrm{Ar}-\mathrm{Cl}_{2}, \mathrm{ArNO}_{2}, \mathrm{Ar}-\mathrm{COOH}$

$\mathrm{R}_{2}$ and $\mathrm{R}_{3}=$ acetone, cyclohexanone, acetophenone

$\mathrm{R}_{4}=$ aliphatic, alicyclic, aromatic

(xix) $\mathrm{Fe}_{3} \mathrm{O}_{4} / \mathrm{SiO}_{2}$, EtOH, rt., 3-6h, reflux

Scheme 15: Synthesis of diazepines, 2.11.4.

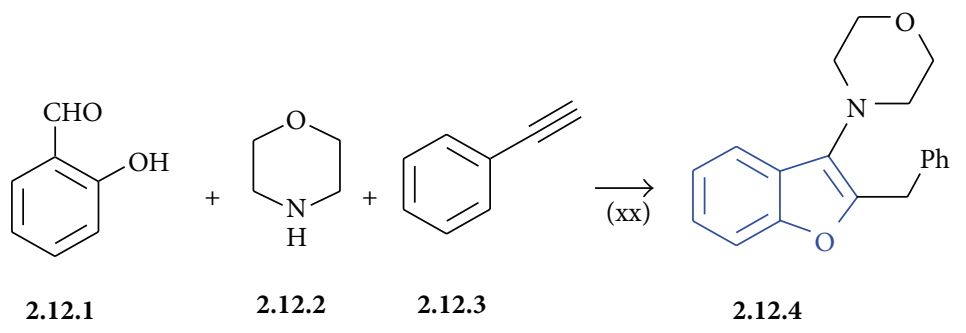

(xx) CuI nanoparticles, $\mathrm{K}_{2} \mathrm{CO}_{3}$, reflux, $1.5 \mathrm{~h}$

SCHEME 16: Synthesis of benzo[b]furans, 2.12.4. 


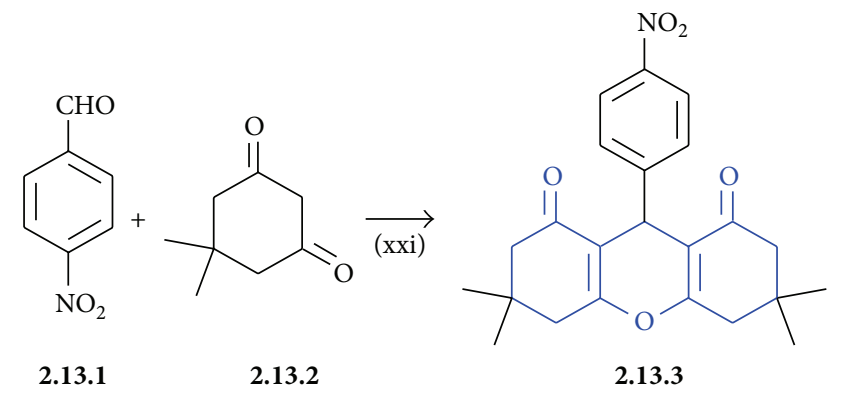

(xxi) MCM-41- $\mathrm{SO}_{3} \mathrm{H}, \mathrm{H}_{2} \mathrm{O}$, sonication

SCHEME 17: Synthesis of 1,8-dioxo-octahydroxanthenes, 2.13.3.

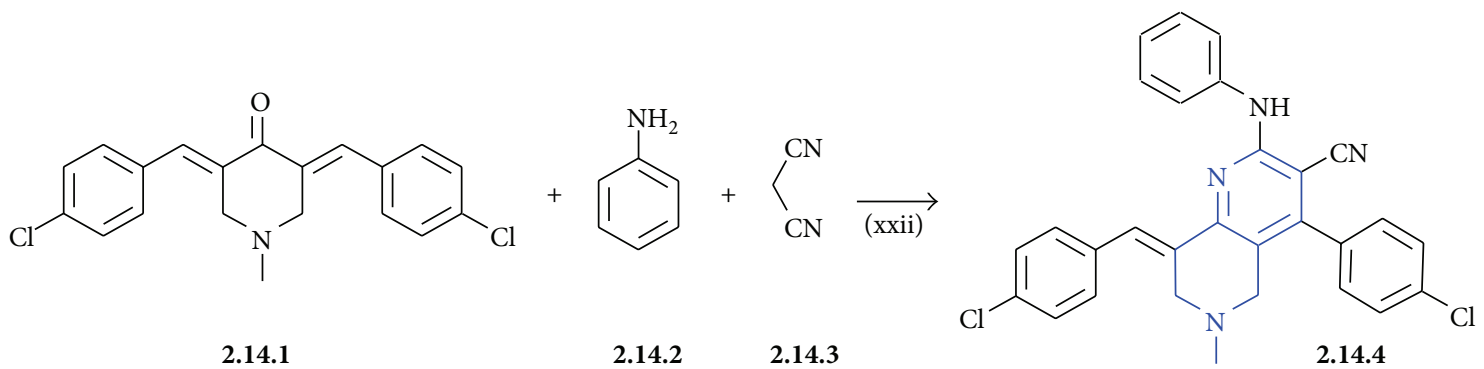

(xxii) $\alpha-\mathrm{Fe}_{2} \mathrm{O}_{3}-\mathrm{MCM}-41-\mathrm{SO}_{3} \mathrm{H}$, solvent free, $120^{\circ} \mathrm{C}$

Scheme 18: Synthesis of 1,6-naphthyridine analogues, 2.14.4.

ligands complexes were tested, but only copper was found to be catalytically active due to the richness of electron on metal. Water was found to be an effective solvent, and also the amount of water is also an important criterion. The optimum amount of water required was found to be $5 \mathrm{~mL}$ for the reaction between styrene oxide, 2.5.6, sodium azide, 2.5.1 and phenyl acetylene, 2.5.5 [59]. Another environment friendly synthesis of triazoles was the cyclisation reaction between three components benzyl bromide 2.5.3, sodium azide 2.5.1, and phenyl acetylene 2.5.5 in the presence of magnetically separable $\mathrm{CuFe}_{2} \mathrm{O}_{4}$ nanoparticles, water at $70^{\circ} \mathrm{C}$. The catalyst can be separated easily and reused effectively [60]. In an alternative method, various copper salts [CuI, $\mathrm{CuSO}_{4}, \mathrm{CuCl}_{2}, \mathrm{Cu}\left(\mathrm{NO}_{3}\right)_{2}, \mathrm{Cu}_{2}-\beta$-CD complex] were used for the synthesis of 1,2,3-triazoles of phenyl boronic acid from coupling of aryl boronic acids, 2.5.7, sodium azide, 2.5.1 and phenyl acetylene, 2.5.5. Among these cooper catalyst $\mathrm{Cu}_{2}-\beta$-CD complex gave excellent yield of 1,2,3-triazole, 2.5.8 without adding any additives [61].

2.6. Synthesis of Coumarins. Coumarins are attractive molecule in chemistry with anti-inflammatory activity [62], antioxidant and lipoxygenase inhibitory activity [63], and antifungal activity [64]. Coumarin has been used as an aroma enhancer in pipe tobaccos and alcoholic drinks although in general it is banned as a flavorant food additive, due to concerns about coumarin's hepatotoxicity in animal models. The synthesis of coumarins and its analogues has attracted extensive thought from organic and medicinal chemists for many years as a large number of natural products contains this heterocyclic nucleus. Moreover, coumarins have various pharmacological activities (Figure 3). Knoevenagel condensation is one of the widely used reactions for the synthesis of coumarins (Scheme 8). Since it involves the use of acids and bases, an alternative approach for carrying out the condensation is essential. The reaction between ohydroxy benzaldehyde, 2.6.1, and 1,3-dicarbonyl compounds, 2.6.2, is an effective reaction for the formation of coumarins, 2.6.3. $\mathrm{ZnO}$ nanoparticles were found to be an effective alternative in $10 \%$ mol concentration. Increase or decrease in the concentration of the $\mathrm{ZnO}$ extends the time taken for the reaction with fewer yields [65].

2.7. Synthesis of Biscoumarins. Transition metal nanoparticles have gained tremendous importance due to their interesting electrical, optical, magnetic, chemical properties, and especially catalytic properties, which cannot be achieved by their bulk counterparts. Recently, there has been growing interest in using nickel nanoparticles in organic synthesis owing to their easy preparation, potent catalytic activity, possible process ability, and high stability. Heterocyclic systems are common structural motifs in many biologically active substances and natural products and therefore warrant the design of newer and efficient protocols for their synthesis. In view of this biscoumarins is an important molecule which possesses anticoagulant activity (Scheme 9) [66]. Khurana 


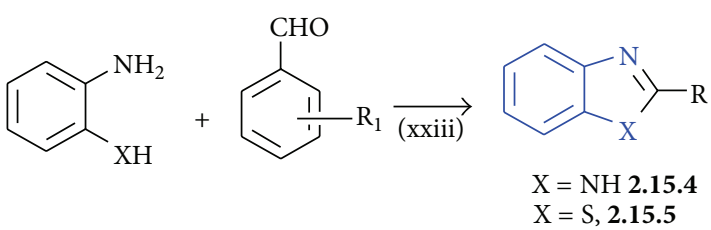

$\mathrm{X}=\mathrm{N}$ 2.15.1 $\quad \mathrm{R}_{1}=\mathbf{2 . 1 5 . 3}$

$\mathrm{X}=\mathrm{S}$ 2.15.2 $\quad \mathrm{R}_{1}=\mathrm{Cl}, \mathrm{NO}_{2}, \mathrm{Me}, \mathrm{OMe}$

(xxiii) CdSMn-doped CdS nanoparticles, Au nanoparticles/C, stirring, $90^{\circ} \mathrm{C}$

SCHeme 19: Synthesis of benzimidazoles, 2.15.4 and benzothiazoles, 2.15.5.

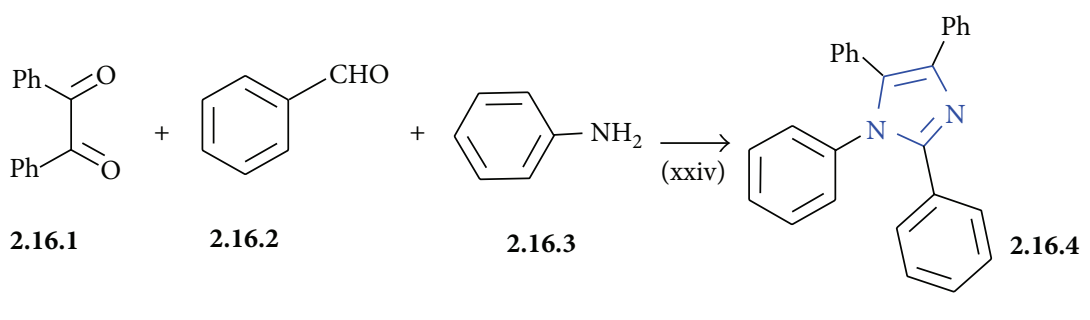

(xxiv) $\mathrm{TiCl}_{4}, \mathrm{SiO}_{2}, \mathrm{SBA}-\mathrm{Pr}-\mathrm{SO}_{3} \mathrm{H}, \mathrm{MgAl}_{2} \mathrm{O}_{4}$, sulfated zirconia, MCM-41-SO $\mathrm{S}_{3}, \mathrm{Fe}_{2} \mathrm{O}_{3}$

Scheme 20: Synthesis of imidazoles, 2.16.5 and 2.16.6.

and Vij performed the synthesis of biscoumarins, 2.7.3, via Knoevenagel condensation followed by rapid Michael addition using polyvinyl pyrrolidone-(PVP)-stabilized nickel nanoparticles for the reactions of aldehydes, 2.7.1, with 4hydroxycoumarin, 2.7.2, in ethylene glycol at room temperature [67].

2.8. Synthesis of Naphthoxazinones. Naphthoxazine, an important motif in heterocyclic chemistry, has reported cytotoxic and antifungal activities [68]. An efficient protocol for the synthesis of 2-naphthol-condensed 1,3-oxazinone, 2.8.4, (Scheme 10) by the reaction between benzaldehyde, 2.8.1, urea, 2.8.2, and $\beta$-naphthol, 2.8.3, was carried out in the presence of $\mathrm{K}_{2} \mathrm{CO}_{3}$ and copper nanoparticles stabilized by PEG-400. In the absence of $\mathrm{Cu}$, the reaction was not initiated. When the same reaction was carried out without PEG400 , the yield was only $30 \%$. Due to various drawbacks of results with the solvents such as DMSO, acetonitrile, ethanol, THF, and ethylene glycol, the ideal solvent for the synthesis of naphthoxazinones was found to be PEG-400. Not does only it act as a solvent, but also it provides stability to $\mathrm{Cu}$ nanoparticles [69].

2.9. Synthesis of Pyran Analogues. Pyran has reported activities such as molluscicidal activity [70] and anthelmintic activity [71]. The synthesis of pyran-annulated heterocyclic systems, 2.9.3 (Scheme 11) can be carried out from various alicyclic/heterocyclic 1,3-dione, 2.9.1, and tetracyanoethylene, 2.9.2, using ecofriendly $\mathrm{TiO}_{2}$ and $\mathrm{TiO}_{2}$ nanoparticles as a catalyst with high yield. Because of the heterogenous nature of $\mathrm{TiO}_{2}$, the work-up process will be carried out easily, and the catalyst can be recovered without any difficulty
[72]. The three-component reaction between aromatic aldehyde, 2.9.4, malononitrile, 2.9.5, 4-hydroxycoumarin, 2.9.7, and $\mathrm{CuO}$ nanoparticles $(15 \% \mathrm{~mol})$ in $10 \mathrm{~mL}$ water is an effective protocol for the synthesis of 3,4dihydropyrano[ $[c]$ chromenes, 2.9.10, (Scheme 12). The same reaction was carried out in the presence of $\mathrm{MgO}, \mathrm{ZnO}$, and $\mathrm{NiO}$, but the reaction in the presence of $\mathrm{CuO}$ was proved to be best in yield [73]. Khoobi and coworkers carried out the synthesis of $4 \mathrm{H}$-benzopyrans, 2.9.11, and 2-amino-5-oxo-4-aryl-4,5-dihydropyrano[3, 2c] chromene-

3-carbonitriles, 2.9.10, (Scheme 12) using the new concept of magnetically inorganic-organic hybrid nanocatalyst, hydroxyapatite-encapsulated $\mathrm{Fe}_{2} \mathrm{O}_{3}$ [74]. A new way of synthesizing $4 \mathrm{H}$-pyrans, 2.9.9, was carried out in ionic liquid using $\mathrm{ZnO} / \mathrm{MgO}$ solid sample containing $\mathrm{ZnO}$ nanoparticles as an innovative catalyst [75]. The $\alpha-\mathrm{Fe}_{2} \mathrm{O}_{3}$ nanopowder was prepared by combustion method and it was used in the synthesis of 3,4-dihydropyrano[c]chromenes, 2.9.10 [76]. MCM-41- $\mathrm{SO}_{3} \mathrm{H}$ has functional groups which forms bonding with 3,5-dibenzyl idenepiperidin-4-one, 2.9.12, and the reactions are initiated inside the nanoreactor along with malononitrile, 2.9.5. The rate of the reaction is increased in the compound, 2.9.12, with electron-withdrawing group and decreases with electron-donating group. The combination of nanosized $\mathrm{MCM}-41-\mathrm{SO}_{3} \mathrm{H}$ and solvent-free atmosphere for the ecofriendly synthesis of pyrano $[3,2-c]$ pyridine derivatives, 2.9.13, (Scheme 13) [77].

2.10. Synthesis of 1,4-Dihydropyridine Derivatives. 1,4-dihydropyridine possesses activity such as calcium channel antagonist activity [78] and antioxidant activity [79]. Synthesis of pyrazolyl 1,4-dihydropyridines (Scheme 14), 2.10.4, was 


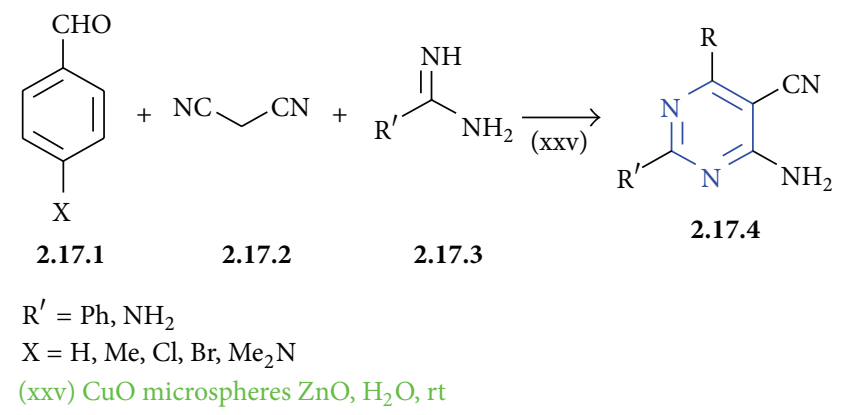

SCHeme 21: Synthesis of pyrimidone carbonitriles, 2.17.4.

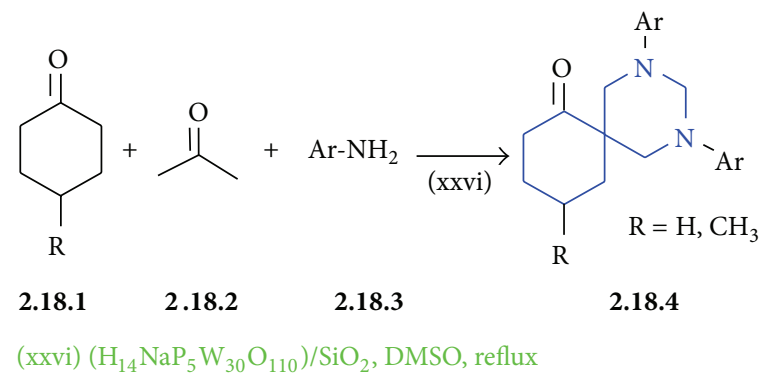

Scheme 22: Synthesis of spirohexapyrimidines, 2.18.4.

carried out by multicomponent reaction between pyrazolyl4-carbaldehyde, 2.10.1, acetoacetic ester, 2.10.2, ammonium acetate, 2.10.3, using 15\% MgO nanotube in the presence of acetonitrile. Even though the reaction was carried in various solvents, usage of acetonitrile-made $\mathrm{MgO}$ nanotube gave the expected product in high yield [80].

2.11. Synthesis of Diazepines. The development of new approaches for the construction of number of heterocycle continues to be essential for accessing natural products and their structural analogues. Among them, 1H-1,4-diazepines derivatives scaffolds over the years have gained an ongoing interest for biological activities as antileukemic, antiviral, antiplatelet, anticancer, anticonvulsant, psychotropics, and herbicidal $[81,82]$. Maleki synthesized one-pot multicomponent synthesis of diazepine derivatives, 2.11.4, (Scheme 15) from readily available 1,2-diamine, 2.11.1, a linear or cyclic ketone, 2.11.2, and an isocyanide, 2.11.3, using magnetically recoverable $\mathrm{Fe}_{3} \mathrm{O}_{4} / \mathrm{SiO}_{2}$ nanocatalyst [83].

2.12. Synthesis of Benzo[b]Furans. Furan ring possesses some important activity such as cytotoxic activity [84] and antibacterial activity [85]. An ecofriendly multicomponent synthesis of benzo[b]furans (Scheme 16) was carried by the condensation reaction between salicylaldehyde, 2.12.1, morpholine, 2.12.2, and phenyl acetylene 2.12.3, using copper iodide nanoparticles as a specific catalyst. The reaction was standardized with various aldehydes, amines, and acetylenes. The result concluded that salicylaldehyde with electron- withdrawing groups, aromatic alkynes and aliphatic amines, gave the desired benzo[b]furans [86].

2.13. Synthesis of 1,8-Dioxo-Octahydroxanthenes. Octahydroxanthenes act as anticancer agents [87]. A classical method for synthesis of 1,8-dioxo-octahydroxanthenes, 2.13.3, (Scheme 17) was the condensation reaction between 4-nitrobenzaldehyde, 2.13.1, and dimedone, 2.13.2, using a combination of ultrasound irradiation and nanosized MCM41- $\mathrm{SO}_{3} \mathrm{H}$ catalyst which leads to increase in the rate of the reaction and yield [88].

2.14. Synthesis of 1,6-Naphthyridine Analogues. Naphthyridine derivatives are reported with antitumour activity [89] and antimicrobial activity [90]. The reactants such as 3,5-bis (4 chlorobenzylidene)-1-methylpiperidin-4-one, 2.14.1, aniline, 2.14.2, and malononitrile, 2.14.3, are mixed together in solvent-free condition. A novel magnetic $\left(\alpha-\mathrm{Fe}_{2} \mathrm{O}_{3}\right)$-MCM$41-\mathrm{SO}_{3} \mathrm{H}$ acts as a nanocatalyst which could be reused even after 5 runs without decrease in activity. This acts as an efficient catalyst for the synthesis of $N$-aryl-2 amino-1,6naphthyridine derivatives, 2.14.4, (Scheme 18) [91].

2.15. Synthesis of Benzimidazoles and Benzothiazoles. The mixture of o-phenylenediamine, 2.15.1, aminothiophenol 2.15.2, and aromatic aldehydes, 2.15.3, in water was stirred at $90^{\circ} \mathrm{C}$ using prepared $\mathrm{CdS}$ and manganese-doped $\mathrm{CdS}$ nanoparticles for the chemoselective synthesis of benzimidazoles, 2.15.4, (Scheme 19) and benzothiazoles, 2.15.5. 

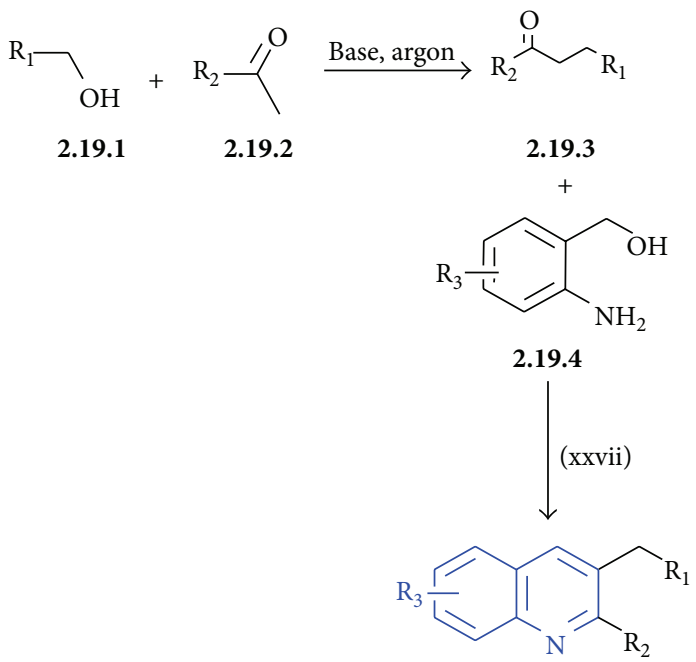

2.19 .5

$\mathrm{R}_{1}=\mathrm{R}_{2}=\mathrm{Ph}, 2 / 3 / 4-\mathrm{MeC}_{6} \mathrm{H}_{4}, 4-\mathrm{OMeC}_{6} \mathrm{H}_{4}, 4-\mathrm{CF}_{3} \mathrm{C}_{6} \mathrm{H}_{4}$

$\mathrm{R}_{3}=\mathrm{Me}$

(xxvii) Ag-Pd/C, base, $\mathrm{O}_{2}$

SCHeme 23: Synthesis of quinoline, 2.19.5.<smiles>[R]C1C(C#N)=C2NC(=O)c3ccccc3N2C2=C1C(=O)CC(C)(C)C2</smiles><smiles>CC1(C)CC(=O)C=C(N)C1</smiles><smiles>CCCCNc1ccccc1C(=O)O</smiles>
(xxviii) 2.19.7

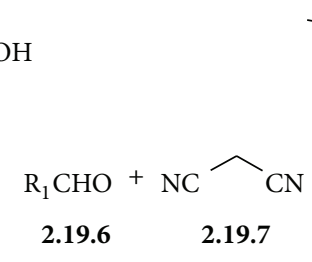

$$
\text { (1) }
$$<smiles>[R]C1C(C#N)=C2NC(=O)C(C)N2C2=C1C(=O)CC(C)(C)C2</smiles>

2.19.11

$\mathrm{R}_{1}=\mathrm{C}_{6} \mathrm{H}_{5}, 4-\mathrm{MeOC}_{6} \mathrm{H}_{4}, 4-\mathrm{BrC}_{6} \mathrm{H}_{4}, 4-\mathrm{ClC}_{6} \mathrm{H}_{4}, 4-\mathrm{MeC}_{6} \mathrm{H}_{4}$
(xxviii) $\mathrm{CuO}$ nanoparticles, $50^{\circ} \mathrm{C}, 30-45 \mathrm{~min}$

Scheme 24: Synthesis of imidazo[1,2-a] quinoline, 2.19.11 and quinolino[1,2-a] quinazoline, 2.19.10.

The doping of Mn increased the activity and selectivity of nanoparticles [92].

2.16. Synthesis of Imidazoles. Imidazoles are present in various pharmacologically active compounds which act as antituberculosis agent [93] and antibacterial agent [94]. They were synthesized as either-trisubstituted or -tetrasubstituted imidazoles by using various reaction conditions such as ultrasonic irradiation [95], TBAB catalyst [96], and $\mathrm{HClO}_{4}{ }^{-}$ $\mathrm{SiO}_{2}$ catalyst [97]. Imidazoles (Scheme 20) can also be obtained by multicomponent reaction using benzil, 2.16.1, aldehydes, 2.16.2, andamines, 2.16.3, in the presence of metal nanoparticles as a catalyst. $\mathrm{TiCl}_{4}$ supported on silica was used as a mild solid Lewis acid for the synthesis of triphenylimidazoles. This catalyst system can be prepared, handled, and stored without any special precautions by maintaining its efficiency. They carried out the reaction under solvent-free condition at $110^{\circ} \mathrm{C}$ for 30 minutes [98]. The solvent-free synthesis of imidazoles was explored with sulfonic acid functionalized SBA-15 as a catalyst. It was found that aliphatic aldehyde gave moderate yield and the aromatic aldehyde with electron-withdrawing and electron-donating groups gave excellent yield in the presence of catalyst and it could be recovered by continuous washing with dilute acid, water, and acetone [99]. A mild Lewis acid catalyst, $\mathrm{MgAl}_{2} \mathrm{O}_{4}$, 


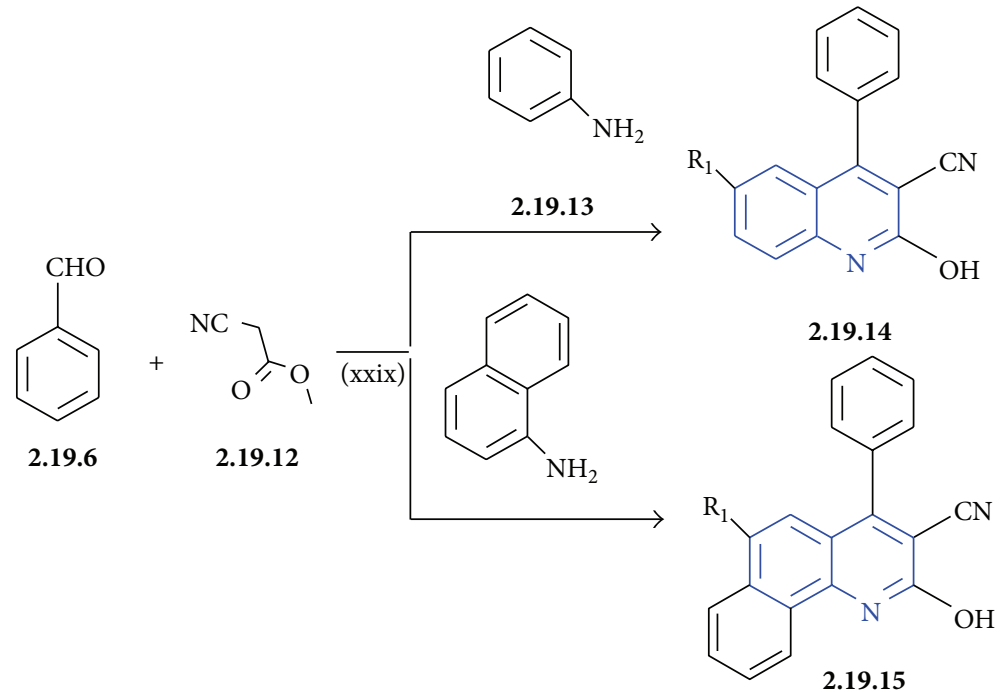

(xxix) $\mathrm{TiO}_{2} \mathrm{NPs}, \mathrm{MW}$

Scheme 25: Synthesis of quinoline-3-carbonitriles, 2.19.14 (or) benzo[h]quinoline-3-carbonitrile, 2.19.15.<smiles>[R]c1c2c(nc3ccccc13)CC([R])([R])CC2=O</smiles>

2.19.20<smiles>[R]C1([R])CC(=O)CC(=O)C1</smiles>

2.19.18 $(\mathrm{xxx})$<smiles>[CH]1CCCCC1</smiles>

2.19.16<smiles>[X]CC(C)=O</smiles>

$\mathrm{X}=\mathrm{CO}_{2} \mathrm{Et}, \mathrm{CO}_{2} \mathrm{Me}, \mathrm{CO}_{2} \mathrm{Bu}, \mathrm{COCH}_{3}$ (xxx) $\mathrm{CuO}, \mathrm{SiO}_{2} \mathrm{NPs}$, stirring, $60^{\circ} \mathrm{C}$

$$
\begin{aligned}
& \mathrm{R}_{1}=\mathrm{R}_{2}=\mathrm{H}, \mathrm{CH}_{3} \\
& \mathrm{R}=\mathrm{Ph}, \mathrm{CH}_{3}
\end{aligned}
$$

SCHeme 26: Friedlander methodology to synthesis of quinoline analogues, 2.19.19-2.19.20.

was utilized for the efficient synthesis of substituted imidazoles under ultrasound irradiation. Because of the decrease in size of the crystal magnesium aluminate, a defect was produced in the coordination of constituent atoms which increases the reactivity of the catalyst, and thereby it leads to cyclocondensation reaction for the formation of imidazoles [100]. The synthesis of imidazole was carried out using clay and zeolite and also with nanocrystalline-sulfated zirconia catalyst in the presence of ethanol at room temperature. The optimization of the reaction condition was performed and found that the yield was increased up to $93 \%$ by the $\mathrm{SZ}$ catalyst [101]. The Bronsted acid nanoreactor, $\mathrm{MCM}-41-\mathrm{SO}_{3} \mathrm{H}$, was involved in the solvent-free synthesis of trisubstituted and tetrasubstituted imidazoles. In this experiment, it was found out that the solvents have no role on the synthesis of imidazoles. The modified action of the nanoreactor increased its efficiency and resulted in higher yield and good reusability [102]. An efficient catalyst, magnetic $\mathrm{Fe}_{3} \mathrm{O}_{4}$ nanoparticles, can also be used for the synthesis of imidazole derivatives. Magnetic $\mathrm{Fe}_{3} \mathrm{O}_{4}$ nanocatalyst and temperature $\left(80^{\circ} \mathrm{C}\right)$ play a crucial role in this reaction under solvent-free condition and gave a maximum yield of up to $96 \%$ [103]. Rostamizadeh and coworkers developed a toxic-free solvent reaction for the synthesis of 2,4,5-trisubstituted and 1,2,4,5-tetra-substituted imidazoles using nanosized $\mathrm{MCM}-41-\mathrm{SO}_{3} \mathrm{H}$ as a catalyst [88].

2.17. Synthesis of Pyrimidine Carbonitriles. The three-component reaction involving aldehydes, 2.17.1, malononitrile, 2.17.2, and amidines, 2.17.3, in the synthesis of 4amino-5-pyrimidinecarbonitriles, 2.17.4, (Scheme 21) was catalyzed using $\mathrm{CuO}$ microspheres. $\mathrm{CuO}$ microspheres are made by granulation of nanoparticles using immobilizationcalcination method [104]. Even though the surface area of microspheres is lesser than nanoparticles, they are larger than bulkier substances. The main purpose of microspheres is to avoid the physical instability of nanoparticles such as agglomeration. The polar solvents such as THF, $\mathrm{CH}_{3} \mathrm{CN}$, and $\mathrm{CH}_{3} \mathrm{CH}_{2} \mathrm{OH}$ gave fewer yields than water in the synthesis of 4-Amino-5-pyrimidinecarbonitriles. 4-amino-5pyrimidinecarbonitriles can also be synthesized using $\mathrm{ZnO}$ 


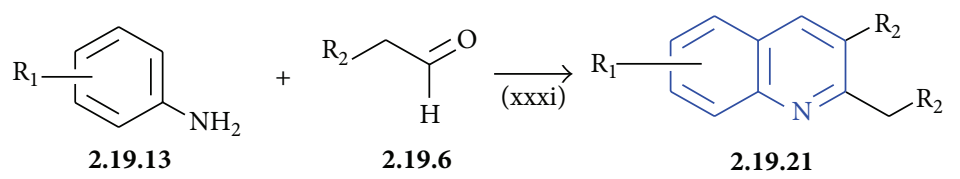

$\mathrm{R}_{1}=\mathrm{CH}_{3}, \mathrm{CH}\left(\mathrm{CH}_{3}\right)_{2}, \mathrm{OCH}_{3}, \mathrm{Ph}, \mathrm{Cl}$

$\mathrm{R}_{2}=\mathrm{C}_{6} \mathrm{H}_{5}$

(xxxi) AuNP/SiO ${ }_{2}, \mathrm{O}_{2}$ bubbling, $110^{\circ} \mathrm{C}, 6 \mathrm{~h}$

Scheme 27: Role of Gold and $\mathrm{SiO}_{2}$ in quinoline synthesis, 2.19.21.

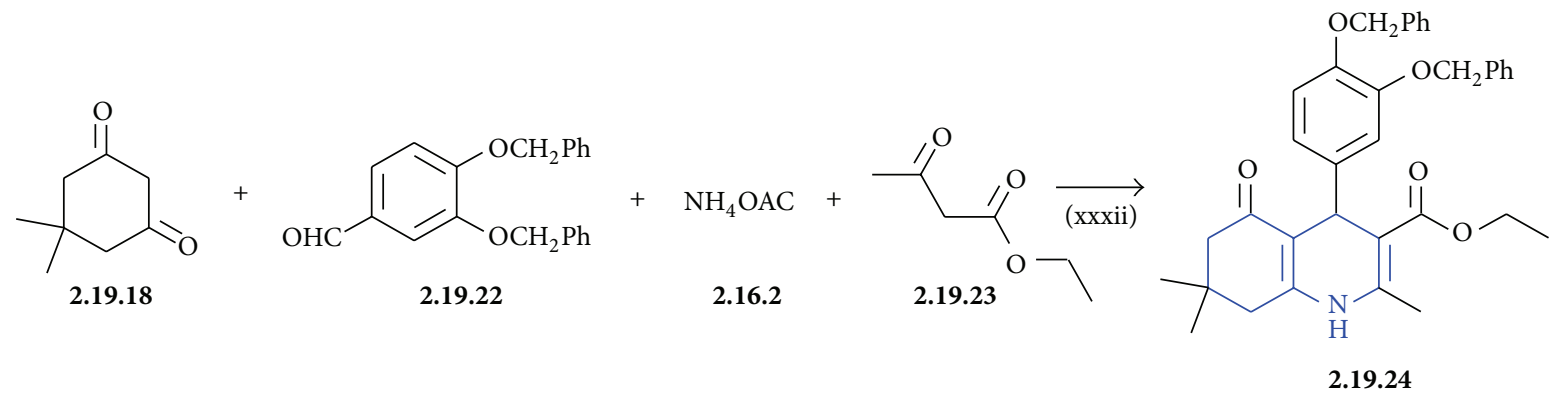

(xxxii) $\mathrm{Fe}_{3} \mathrm{O}_{4}$-Cys, EtOH, $25 \mathrm{~min}$

SCHEme 28: Multicomponent approach in quinoline synthesis, 2.19.24.

nanoparticles. Being insoluble in water and other organic solvents it can be easily recovered from the reaction mixture immediately after the reaction [105].

2.18. Synthesis of Spirohexahydropyrimidines. A one-pot condensation of cyclohexanone, 2.18.1, ketone, 2.18.2, and aniline, 2.18.3, using innovative preyssler nanoparticles, $\mathrm{H}_{14}\left[\mathrm{NaP}_{5} \mathrm{~W}_{30} \mathrm{O}_{110}\right] / \mathrm{Si}$ as an efficient catalyst system for synthesizing 1,3-diaryl-5-spirohexahydropyrimidines, 2.18.4, (Scheme 22) [106].

2.19. Synthesis of Quinoline Analogues. Quinoline nucleus is one of the important constituents which is present in the naturally occurring alkaloids. It has proven antimalarial activity along with many other important pharmacological actions. In the synthesis of polysubstituted quinolines, 2.19.5 (Scheme 23) first step involves the $\alpha$-alkylation of ketone, 2.19.2, with alcohol, 2.19.1, to give saturated ketone, 2.19.3. In the second step, ketone, 2.19.3, undergoes modified Friedlander annulations process with 2-aminobenzyl alcohol, 2.19.4, to get the desired product. Ag-Pd alloy nanoparticles supported on carbon, a comparison of the activity of Ag$\mathrm{Pd} / \mathrm{C}$ catalyst with that of palladium-based nanocatalystscore-shell Ag@Pd/C and Pd/C were studied. At $125^{\circ} \mathrm{C}$, all the catalyst produced more- or less-same yield whereas at $90^{\circ} \mathrm{C}$ $\mathrm{Ag}-\mathrm{Pd} / \mathrm{C}$ catalyst superseded the other two catalysts in yield. This was explained due to the transfer of charge from lesselectronegative Ag metal to more electronegative Pd [107]. An alternative method to synthesize quinoline derivatives such as imidazo[1,2-a] quinoline, 2.19.11, and quinolino[1,2a] quinazoline, 2.19.10, (Scheme 24) is to heat the mixture of aldehyde, 2.19.6, malononitrile, 2.19.7, enaminones, (2.19.8, 2.19.9) at $50^{\circ} \mathrm{C}$ for $30-45$ minutes in the presence of known solid base catalysts, bulk $\mathrm{CuO}$, and $\mathrm{CuO}$ nanoparticles. All the catalyst is except $\mathrm{CuO}$ nanoparticles underwent reaction for a long time with moderate to poor yield. Whereas $\mathrm{CuO}$ nanoparticles produced excellent yield because of its insoluble nature in water, it can be recovered easily [108]. $\mathrm{TiO}_{2}-$ catalyzed synthesis of quinoline-3-carbonitriles, 2.19.14, (or) benzo[h] quinoline-3-carbonitrile, 2.19.15 and (Scheme 25) in the presence of water and microwave irradiation was carried out in an ecofriendly way. These derivatives can be synthesized from arylaldehyde, 2.19.6, cyanoacetate, 2.19.12, anilines, 2.19.13, using knoevenagel condensation, Michael addition followed by aromatization. The report indicated that the nanocatalyst showed superior reactivity than the conventional method [109].

The optimization of Friedlander synthesis of quinolines (Scheme 26) was carried out on various of 2-aminoaryl ketones, 2.19.16, active methylene compounds, 2.19.17, and simple cyclic ketones, 2.19.18, under different catalysts $\left(\mathrm{TiO}_{2}\right.$, $\mathrm{SiO}_{2}, \mathrm{Al}_{2} \mathrm{O}_{3}, \mathrm{ZnO}, \mathrm{MgO}, \mathrm{CuO}$ bulk and nano-CuO) in solvent-free condition at $60^{\circ} \mathrm{C}$, and nano- $\mathrm{CuO}$ was found superior to all the other catalysts [110]. So et al. explored that $\mathrm{AuNPs} / \mathrm{SiO}_{2}+\mathrm{O}_{2}$ as an efficient catalyst system for the synthesis of polyheterocyclic compounds containing nitrogen, 2.19.21 (Scheme 27) from aniline, 2.19.13, and aldehyde, 2.19.6. They performed the mechanistic studies of quinolines and reported that the reaction does not follow the radical pathway, and the yield was very less in the presence of silica alone. Therefore, AuNPs $/ \mathrm{SiO}_{2}+\mathrm{O}_{2}$ protocol is the optimal one for the quinoline synthesis [111]. Ferrite magnetic 
<smiles>[R16]c1ccc(C2C=C(C(=O)O)NC3=C2C(=O)CC([R])([R])C3)cc1</smiles>

$\mathrm{R}_{1}=\mathrm{Cl}, \mathrm{OCH}_{3}, \mathrm{CH}_{3}$

$\mathrm{R}_{2}=\mathrm{H}, \mathrm{Me}$

SCHEME 29: Metal oxide-mediated quinoline analogue synthesis, 2.19.27.

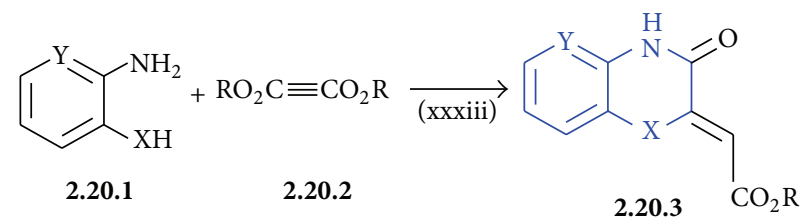

$\mathrm{X}=\mathrm{S}, \mathrm{O}, \mathrm{NH} \quad \mathrm{Y}=\mathrm{CH}, \mathrm{N}$

$\mathrm{R}=\mathrm{CH}_{3}, \mathrm{C}_{2} \mathrm{H}_{5} \quad$ (xxxiii) $\mathrm{CuO}, \mathrm{H}_{2} \mathrm{O}$, stirring, rt

Scheme 30: CuO-mediated various benzoheterocycle synthesis, 2.20.3.

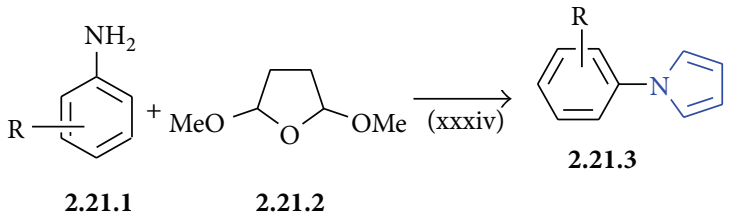

$\mathrm{R}=$ Alkyl, aryl, heterocyclic

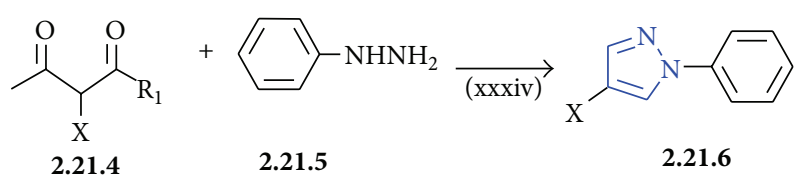

$\mathrm{R}_{1}=\mathrm{Me} \cdot \mathrm{OEt}$

$\mathrm{X}=\mathrm{H}, \mathrm{Et}, \mathrm{Cl}$

(xxxiv) $\mathrm{Fe}_{3} \mathrm{O}_{4}, \mathrm{H}_{2} \mathrm{O}, \mathrm{MW}, 140^{\circ} \mathrm{C}$

Scheme 31: Synthesis of pyrrole, 2.21.3, and pyrazole, 2.21.6.

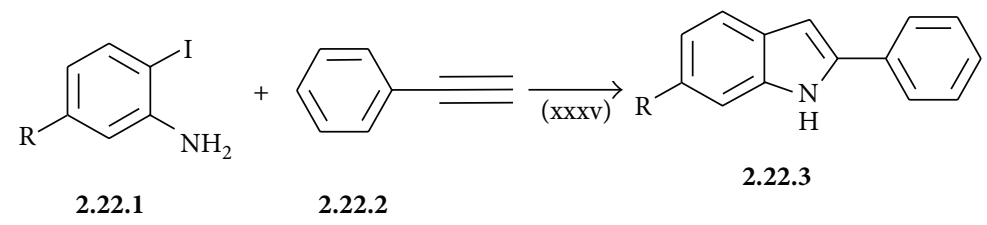

(xxxv) 3\% Pd/MIL-101

Scheme 32: Green synthesis of indole, 2.22.3. 
<smiles>[R3]c1cc([R3])c2c(c1)cc([R])n2[R1]</smiles>

2.23.1<smiles>[R]c1ccc(C2OC2([R])[R])cc1</smiles>

2.23.2

$\mathrm{R}_{5}=\mathrm{H}, \mathrm{Cl}, \mathrm{Br}, \mathrm{F}$ $\mathrm{R}_{6}=\mathrm{R}_{7}=\mathrm{H}$

(xxxvi) $\mathrm{Fe}_{3} \mathrm{O}_{4}$ as catalyst

Scheme 33: C-alkylation of indole using $\mathrm{Fe}_{2} \mathrm{O}_{3}$, 2.23.3.

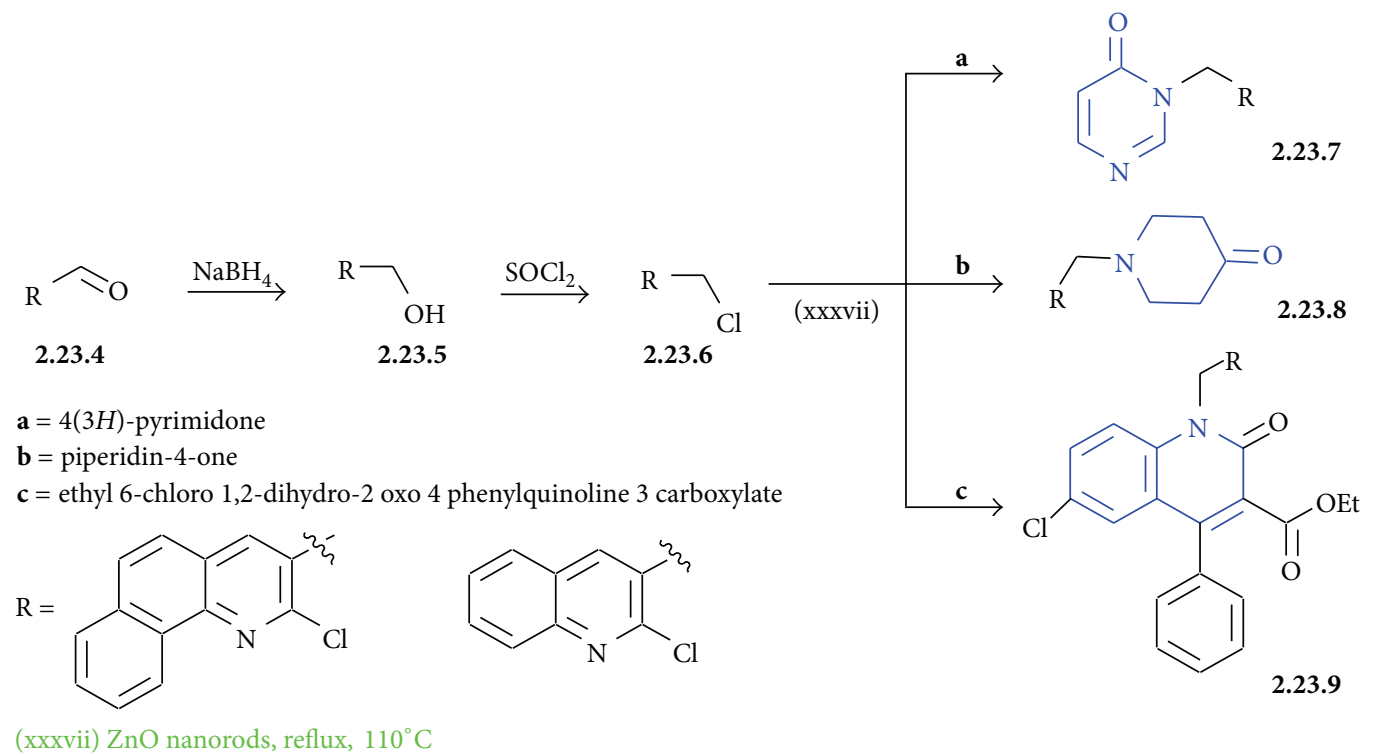

Scheme 34: Cross-coupling reaction, 2.23.7-2.23.9.

nanoparticles with cysteine can be used as catalyst for the Hantzsch synthesis of hydroquinolines, 2.19.24, (Scheme 28) in a multicomponent reaction between 3,4 diphenoxy benzaldehyde, 2.19.22, ammonium acetate, 2.16.2, ethyl acetoacetate, 2.19.23, and 5,5-dimethylcyclohexane-1,3-dione, 2.19.18. The yield was up to $88 \%$, and it could be reused with unaltered activity until 9 cycles [112]. Abdolmohammadi developed and green friendly protocol for the synthesis of 5-oxo-4-aryl-1,4,5,6,7,8-hexahydro-2-quinolinecarboxylic acid, 2.19.27 (Scheme 29) using $\mathrm{TiO}_{2}$ nanoparticles under solvent-free conditions [113].

2.20. Synthesis of Benzoheterocycle Derivatives. CuO nanoparticles are capable of synthesizing various compounds which has both pharmacological and industrial applications. In the benzoheterocycles, 2.20.3 (Scheme 30) formation, reaction between aromatic amine, 2.20.1, and dialkyl acetylenedicarboxylate, 2.20.2, catalyzed by $\mathrm{CuO}$ nanoparticles was optimized by various solvents (water, dichloromethane, ethanol, and acetonitrile). Water excels in yield more than the other solvents. $\mathrm{CuO}$ has both oil- and water-resistant character. So it can be reused by easy recycling process without losing its efficiency [114].

2.21. Synthesis of Pyrrole and Pyrazole. Nanoparticles combined with organic compounds constitute a vital role in organic synthesis. Here, the magnetic nanoparticles are modified with aminoacids such as cysteine and glutathione. Both aminoacids have highly reactive thiol group which can easily functionalize the nanoferrite surface. Of the two aminoacids, glutathione is superior to cysteine in reactivity. The active sites of the nanocatalyst were left free for catalyzing the reaction. This catalyst can be applied in the Paal-Knorr reactions of pyrrole, 2.21.3, (Scheme 31) synthesis between variety of amines, 2.21.1, and tetrahydro-2,5-dimethoxyfuran, 2.21.2. Also this catalyst can be used in the synthesis of pyrazole, 2.21.6, between 1,3-diketone, 2.21.4, and hydrazines, 2.21.5. The entire reaction was carried out in toxic-free solvent (water) and effective microwave irradiation [115]. 
<smiles>O=CCc1cc2ccc3ccccc3c2nc1Cl</smiles>

2.23.10<smiles>OCc1cc2ccc3ccccc3c2nc1Cl</smiles>

2.23.11

(xxxviii) $\mathrm{ZnO}, \mathrm{NaBH}_{4}, \mathrm{H}_{2} \mathrm{O}, \mathrm{RT}$

Scheme 35: ZnO nanoparticles mediated reduction of quinoline-3-carbaldehyde, 2.23.11.<smiles>CC(=O)c1c(-c2ccccc2)c2cc(Cl)ccc2[nH]c1=O</smiles>

2.23.12<smiles>[R][X]1=C=Cc2cc(Cl)c(C(C)(C)C)cc2C=C1</smiles>

$\mathrm{X}=\mathrm{CH}_{3}, \mathrm{OCH}_{3}$

(xxxix) $\mathrm{Ag}, \mathrm{DMSO}, 110^{\circ} \mathrm{C}$<smiles>[R]CCCCCCO</smiles><smiles>[R]COc1nc2ccc(Cl)cc2c(-c2ccccc2)c1C(C)=O</smiles>

2.23.13

2.23.14

Scheme 36: O-alkylation of quinoline, 2.23.14.

2.22. Synthesis of Indole. Synthesis of indole was carried out using an innovative catalyst, $\mathrm{Pd}$ supported on the cages of MIL-101 $\left[\mathrm{Cr}_{3} \mathrm{~F}\left(\mathrm{H}_{2} \mathrm{O}\right)_{2} \mathrm{O}(\mathrm{bdc})_{3}\right]$. This support is more water soluble than the other inorganic supports. Thereby, the reactions in aqueous solution will be catalyzed effectively. The reaction between 2-iodoanilines, 2.22.1, and phenyl acetylene, 2.22.2, in the presence of 3\%-Pd/MIL-101 will lead to the formation of indole, 2.22.3, (Scheme 32). In addition, the substituents on the ring will have an effect on the current reaction medium [116].

\subsection{Miscellaneous Functionalization on Heterocycles.} Parella and coworkers carried out the C-alkylation reaction (Scheme 33) of indoles, 2.23.1, with epoxide, 2.23.2, using the magnetic nano- $\mathrm{Fe}_{3} \mathrm{O}_{4}$ as a catalyst [117]. Roopan and Khan explored an efficient ligand-free cross-coupling reaction of 2-chloro-3-(chloromethyl) benzo[ $h]$ quinoline, 2.23.6, with $\mathrm{N}$-heterocycles such as piperidin-4-one, 4(3H)-pyrimidone, and ethyl 6-chloro-1,2-dihydro-2-oxo-4-phenylquinoline-3-carboxylate using a catalytic amount of $\mathrm{ZnO}$ nanorods as a recyclable catalyst to give its corresponding derivatives, 2.23.7-2.23.9 (Scheme 34), respectively [118]. The possible mechanism is described in Figure 4. The chloromethyl derivative of quinoline, 2.23.6, is obtained from hydroxymethyl derivative, 2.23.5, which in turn is obtained from aldehyde, 2.23.4. The reduction of 2-chloroquinoline3-carbaldehydes, 2.23.10, into (2-chloroquinolin-3-yl) methanol, 2.23.11, occurs using zinc oxide nanoparticles as a catalyst in an ecofriendly way (Scheme 35) [1]. Roopan and coworkers synthesized 1-\{2-[(2-chloroquinolin-3-yl) methoxy]-6-chloro-4phenylquinolin-3-yl\} ethanones, 2.23.14, (Scheme 36) from heteroalkylhalides, 2.23.13, and cyclic amides, 2.23.12, using silver nanoparticles in regioselective $\mathrm{O}$-alkylation reaction [119]. Furthermore, they have used Fe nanoparticle for the regioselective N-alkylation of $4(3 \mathrm{H})$ pyrimidone, 2.23.17, (Scheme 37) with various quinoline containing alkyl halides in an ecofriendly way. The possible mechanism is described in Figure 5. [120].

\section{Conclusions}

This review is the first attempt to compile the literature on the subject of nanomaterials application in organic synthesis. It should be noted that a correct and update citation and literature survey is very important for researchers to find relevant information, pioneer ideas, and progress of any subject. On the other hand, published data using nanomaterials indicate a wide synthetic potential of the described catalysts and a great interest of researchers in this field. The use of green nanocatalyst for the synthesis of various heterocycles has advantages such as short reaction time, high yield, inexpensive chemicals usage, easy work-up procedure, and very specific reaction [2]. The use of nanocatalyst can also be applied on the synthesis of various heterocycles which 
<smiles></smiles>

(XL) $\mathrm{Fe}, \mathrm{KOH}, \mathrm{DMSO}, 110^{\circ} \mathrm{C}$

SCHEme 37: Regioselective alkylation reaction towards pyrimidone molecule, 2.23.17.

are very difficult to prepare by conventional methods. Also more and transition metals can be checked for its catalytic activity and surface modifications of the existing catalyst can also be performed. In most of the reactions the spent catalyst can be easily separated from the reaction mixture, also it can be reused without noticeable change in its catalytic activity. A wide range of original procedures for synthesizing various classes of organic compounds, including organic functional group transformation, have been developed on the basis of nanoparticles. We assume that the present review article may be bringing a basis to advance information to this very important subject and to encourage active researchers in this field for the synthesis of organic compounds using nanoparticles.

\section{Acknowledgments}

The authors thank the management of VIT University for their support and encouragement. Furthermore, the authors thank their coworkers, named, in the references, for their experimental and intellectual contributions.

\section{References}

[1] S. M. Roopan and F. R. N. Khan, "ZnO nanoparticles in the synthesis of $\mathrm{AB}$ ring core of camptothecin," Chemical Papers, vol. 64 , no. 6 , pp. 812-817, 2010.

[2] G. Madhumitha and S. M. Roopan, "Devastated crops: multifunctional efficacy for the production of nanoparticles," Journal of Nanomaterials, vol. 2013, pp. 1-12, 2013.

[3] L. Sang-Bum, P. Young In, D. Mi-Sook, and G. Young-Dae, "Identification of 2,3,6-trisubstituted quinoxaline derivatives as a Wnt $2 / \beta$-catenin pathway inhibitor in non-small-cell lung cancer cell lines," Bioorganic \& Medicinal Chemistry Letters, vol. 20, pp. 5900-5904, 2010.

[4] N. M. Sabry, H. M. Mohamed, E. S. A. E. H. Khattab, S. S. Motlaq, and A. M. El-Agrody, "Synthesis of $4 H$-chromene, coumarin, $12 H$-chromeno[2,3-d]pyrimidine derivatives and some of their antimicrobial and cytotoxicity activities," European Journal of Medicinal Chemistry, vol. 46, no. 2, pp. 765-772, 2011.

[5] R. Raj, P. Singh, P. Singh, J. Gut, P. J. Rosenthal, and V. Kumar, "Azide-alkyne cycloaddition en route to $1 H-1,2,3-$ triazole-tethered 7-chloroquinoline-isatin chimeras: synthesis and antimalarial evaluation," European Journal of Medicinal Chemistry, vol. 62, pp. 590-596, 2013.
[6] M. M. Sitônio, C. H. Carvalho Jr., I. A. Campos et al., "Antiinflammatory and anti-arthritic activities of 3, 4-dihydro-2, 2dimethyl-2 $H$-naphthol[1,2-b]pyran-5, 6-dione ( $\beta$-lapachone)," Inflammation Research, vol. 62, pp. 107-113, 2013.

[7] R. Ghorbani-Vaghei and S. M. Malaekehpoor, "N- Bromosuccinimide as an efficient catalyst for the synthesis of indolo [2,3-b lquinolines," Tetrahedron Letters, vol. 53, pp. 4751-4753, 2012.

[8] K. Rad-Moghadam and S. C. Azimi, " $\mathrm{Mg}\left(\mathrm{BF}_{4}\right)_{2}$ doped in $[\mathrm{BMIm}]\left[\mathrm{BF}_{4}\right]$ : a homogeneous ionic liquid-catalyst for efficient synthesis of 1, 8-dioxo-octahydroxanthenes, decahydroacridines and 14-aryl-14 H-dibenzo[a, j]xanthenes," Journal of Molecular Catalysis A, vol. 363-364, pp. 465-469, 2012.

[9] T. S. Jin, J. C. Xiao, S. J. Wang, and T. S. Li, "Ultrasound-assisted synthesis of 2-amino-2-chromenes with cetyltrimethylammonium bromide in aqueous media," Ultrasonics Sonochemistry, vol. 11, no. 6, pp. 393-397, 2004.

[10] C. L. Ni, X. H. Song, H. Yan, X. Q. Song, and R. G. Zhong, "Improved synthesis of diethyl 2,6-dimethyl-4-aryl-4H-pyran3,5-dicarboxylate under ultrasound irradiation," Ultrasonics Sonochemistry, vol. 17, no. 2, pp. 367-369, 2010.

[11] G. Chen, H. Jia, L. Zhang, B. Chen, and J. Li, "An efficient synthesis of 2-substituted benzothiazoles in the presence of $\mathrm{FeCl}_{3}$ /Montmorillonite K-10 under ultrasound irradiation," Ultrasonics Sonochemistry, vol. 20, pp. 627-632, 2013.

[12] A. Lak, M. Mazloumi, M. S. Mohajerani et al., "Rapid formation of mono-dispersed hydroxyapatite nanorods with narrow-size distribution via Microwave Irradiation," Journal of the American Ceramic Society, vol. 91, no. 11, pp. 3580-3584, 2008.

[13] M. S. Mohajerani, M. Mazloumi, A. Lak, A. Kajbafvala, S. Zanganeh, and S. K. Sadrnezhaad, "Self-assembled zinc oxide nanostructures via a rapid microwave-assisted route," Journal of Crystal Growth, vol. 310, no. 15, pp. 3621-3625, 2008.

[14] R. Narayanan, "Synthesis of green nanocatalysts and industrially important green reactions," Green Chemistry Letters and Reviews, vol. 5, pp. 707-725, 2012.

[15] R. M. Mohamed, D. L. McKinney, and W. M. Sigmund, "Enhanced nanocatalysts," Materials Science and Engineering R, vol. 73, pp. 1-13, 2012.

[16] M. Mazloumi, N. Shahcheraghi, A. Kajbafvala et al., “3D bundles of self-assembled lanthanum hydroxide nanorods via a rapid microwave-assisted route," Journal of Alloys and Compounds, vol. 473, no. 1-2, pp. 283-287, 2009.

[17] A. Kajbafvala, H. Ghorbani, A. Paravar, J. P. Samberg, E. Kajbafvala, and S. K. Sadrnezhaad, "Effects of morphology on photocatalytic performance of zinc oxide nanostructures synthesized by rapid microwave irradiation methods," Superlattices and Microstructures, vol. 51, pp. 512-522, 2012.

[18] M. R. Bayati, R. Molaei, A. Kajbafvala, S. Zanganeh, H. R. Zargar, and K. Janghorban, "Investigation on hydrophilicity 
of micro-arc oxidized $\mathrm{TiO}_{2}$ nano/micro-porous layers," Electrochimica Acta, vol. 55, no. 20, pp. 5786-5792, 2010.

[19] A. Kajbafvala, J. P. Samberg, H. Ghorbani, E. Kajbafvala, and S. K. Sadrnezhaad, "Effects of initial precursor and microwave irradiation on step-by-step synthesis of zinc oxide nano architectures," Materials Letters, vol. 67, pp. 342-345, 2012.

[20] M. Mazloumi, S. Zanganeh, A. Kajbafvala et al., "Ultrasonic induced photoluminescence decay in sonochemically obtained cauliflower-like $\mathrm{ZnO}$ nanostructures with surface $1 \mathrm{D}$ nanoarrays," Ultrasonics Sonochemistry, vol. 16, no. 1, pp. 11-14, 2009.

[21] S. Zanganeh, A. Kajbafvala, N. Zanganeh et al., "Hydrothermal synthesis and characterization of $\mathrm{TiO}_{2}$ nanostructures using LiOH as a solvent," Advanced Powder Technology, vol. 22, no. 3, pp. 336-339, 2011.

[22] A. Kajbafvala, S. Zanganeh, E. Kajbafvala, H. R. Zargar, M. R. Bayati, and S. K. Sadrnezhaad, "Microwave-assisted synthesis of narcis-like zinc oxide nanostructures," Journal of Alloys and Compounds, vol. 497, no. 1-2, pp. 325-329, 2010.

[23] A. Kajbafvala, M. R. Shayegh, M. Mazloumi et al., "Nanostructure sword-like $\mathrm{ZnO}$ wires: rapid synthesis and characterization through a microwave-assisted route," Journal of Alloys and Compounds, vol. 469, no. 1-2, pp. 293-297, 2009.

[24] A. Lak, M. Mazloumi, M. Mohajerani et al., "Self-assembly of dandelion-like hydroxyapatite nanostructures via hydrothermal method," Journal of the American Ceramic Society, vol. 91, no. 10, pp. 3292-3297, 2008.

[25] S. Zanganeh, A. Kajbafvala, N. Zanganeh et al., "Self-assembly of boehmite nanopetals to form 3D high surface area nanoarchitectures," Applied Physics A, vol. 99, no. 1, pp. 317-321, 2010.

[26] M. Mazloumi, M. Attarchi, A. Lak et al., "Boehmite nanopetals self assembled to form rosette-like nanostructures," Materials Letters, vol. 62, no. 26, pp. 4184-4186, 2008.

[27] S. Zanganeh, M. Torabi, A. Kajbafvala et al., "CVD fabrication of carbon nanotubes on electrodeposited flower-like Fe nanostructures," Journal of Alloys and Compounds, vol. 507, no. 2, pp. 494-497, 2010.

[28] Y. Estevez, M. Quiliano, A. Burguete et al., "Trypanocidal properties, structure-activity relationship and computational studies of quinoxaline 1,4-di- $N$-oxide derivatives," Experimental Parasitology, vol. 127, pp. 745-751, 2011.

[29] E. Vicente, P. R. Duchowicz, E. A. Castro, and A. Monge, "QSAR analysis for quinoxaline-2-carboxylate 1,4-di- $N$-oxides as anti-mycobacterial agents," Journal of Molecular Graphics and Modelling, vol. 28, no. 1, pp. 28-36, 2009.

[30] H. Yoo, Y. Lee, M. E. Suh, D. J. Kim, and S. W. Park, "Cytotoxic effects of quinoxaline derivatives on human cancer cell lines," Archiv Der Pharmazie, vol. 331, pp. 331-333, 1998.

[31] M. J. Climent, A. Corma, J. C. Hernández, A. B. Hungría, S. Iborra, and S. Martínez-Silvestre, "Biomass into chemicals: one-pot two- and three-step synthesis of quinoxalines from biomass-derived glycols and 1,2-dinitrobenzene derivatives using supported gold nanoparticles as catalysts," Journal of Catalysis, vol. 292, pp. 118-129, 2012.

[32] A. Hasaninejad, M. Shekouhy, and A. Zare, "Silica nanoparticles efficiently catalyzed synthesis of quinolines and quinoxalines," Catalysis Science \& Technology, vol. 2, pp. 201-214, 2012.

[33] B. B. F. Mirjalili, A. Bamoniri, and A. Akbari, "Nano- $\mathrm{BF}_{3} \cdot \mathrm{SiO}_{2}$ : a reusable and eco-friendly catalyst for synthesis of quinoxalines," Chemistry of Heterocyclic Compounds, vol. 47, pp. 487-491, 2011.

[34] B. B. F. Mirjalili and A. Akbari, "Nano- $\mathrm{TiO}_{2}$ : an eco-friendly alternative for the synthesis of quinoxalines," Chinese Chemical Letters, vol. 22, no. 6, pp. 753-756, 2011.
[35] H. Y. Lü, S. H. Yang, J. Deng, and Z. H. Zhang, "Magnetic $\mathrm{Fe}_{3} \mathrm{O}_{4}$ nanoparticles as new, efficient, and reusable catalysts for the synthesis of quinoxalines in water," Australian Journal of Chemistry, vol. 63, no. 8, pp. 1290-1296, 2010.

[36] A. A. Yelwande, M. E. Navgire, B. R. Arbad, and M. K. Lande, "Polyaniline $/ \mathrm{SiO}_{2}$ nanocomposite catalyzed efficient synthesis of quinoxaline derivatives at room temperature," Journal of the Chinese Chemical Society, vol. 59, pp. 1-6, 2012.

[37] H. Alinezhad, M. Tajbakhsh, F. Salehian, and P. Biparva, "Synthesis of quinoxaline derivatives using $\mathrm{TiO}_{2}$ nanoparticles as an efficient and recyclable catalyst," Bulletin of the Korean Chemical Society, vol. 32, pp. 3720-3725, 2011.

[38] A. Kumar, S. kumar, A. Saxena, A. De, and S. Mozumdar, "Ni-nanoparticles: an efficient catalyst for the synthesis of quinoxalines," Catalysis Communications, vol. 9, no. 5, pp. 778784, 2008.

[39] G. R. Bardajee, R. Malakooti, I. Abtin, and H. Atashin, "Palladium Schiff-base complex loaded SBA-15 as a novel nanocatalyst for the synthesis of 2,3-disubstituted quinoxalines and pyridopyrazine derivatives," Microporous and Mesoporous Materials, vol. 169, pp. 67-74, 2013.

[40] B. L. Finkelstein and C. J. Strock, "Synthesis and insecticidal activity of novel pyrazole methanesulfonates," Pesticide Science, vol. 50, no. 4, pp. 324-328, 1997.

[41] C. M. R. De Sant'anna, R. B. De Alencastro, C. R. Rodrigues et al., "A semiempirical study of pyrazole acylhydrazones as potential antimalarial agents," International Journal of Quantum Chemistry, vol. 60, no. 8, pp. 1835-1843, 1996.

[42] A. A. Farghaly, A. A. Bekhit, and J. Y. Park, "Design and synthesis of some oxadiazolyl, thiadiazolyl, thiazolidinyl, and thiazolyl derivatives of $1 H$-pyrazole as anti-inflammatory antimicrobial agents," Archiv der Pharmazie, vol. 333, no. 2-3, pp. 53-57, 2000.

[43] F. N. Khan, J. S. Jin, T. Maiyalagan et al., "Iron-oxide nanoparticles mediated cyclization of 3-(4-chlorophenyl)-1-hydrazinylisoquinoline to 1-(4,5-dihydropyrazol-1-yl)isoquinolines," Research on Chemical Intermediates, vol. 38, pp. 571-582, 2012.

[44] S. Rostamizadeh, N. Shadjou, M. Azad, and N. Jalali, “( $\alpha$ $\mathrm{Fe}_{2} \mathrm{O}_{3}$ )-MCM-41 as a magnetically recoverable nanocatalyst for the synthesis of pyrazolo[4,3-c]pyridines at room temperature," Catalysis Communications, vol. 26, pp. 218-224, 2012.

[45] J. R. Goodell, A. A. Madhok, H. Hiasa, and D. M. Ferguson, "Synthesis and evaluation of acridine- and acridone-based antiherpes agents with topoisomerase activity," Bioorganic and Medicinal Chemistry, vol. 14, no. 16, pp. 5467-5480, 2006.

[46] M. Jones, A. E. Mercer, P. A. Stocks et al., "Antitumour and antimalarial activity of artemisinin-acridine hybrids," Bioorganic and Medicinal Chemistry Letters, vol. 19, no. 7, pp. 2033-2037, 2009.

[47] S. M. Roopan, R. Subashini, A. Bharathi, G. Rajakumar, A. A. Rahuman, and P. K. Gullanki, "Synthesis, spectral characterization and larvicidal activity of acridin-1 $(2 H)$-one analogues," Spectrochimica Acta A, vol. 95, pp. 442-445, 2012.

[48] S. M. Roopan and F. R. N. Khan, " $\mathrm{SnO}_{2}$ nanoparticles mediated nontraditional synthesis of biologically active 9-chloro6, 13-dihydro-7-phenyl-5H-indolo[3, 2-c]-acridine derivatives," Medicinal Chemistry Research, vol. 20, pp. 732-737, 2011.

[49] M. A. Ghasemzadeh, J. Safaei-Ghomi, and H. Molaei, " $\mathrm{Fe}_{3} \mathrm{O}_{4}$ nanoparticles: as an efficient, green and magnetically reusable catalyst for the one-pot synthesis of 1,8-dioxo-decahydroacridine derivatives under solvent-free conditions," Comptes Rendus Chimie, vol. 15, pp. 969-974, 2012. 
[50] S. Rostamizadeh, A. Amirahmadi, N. Shadjou, and A. M. Amani, "MCM-41- $\mathrm{SO}_{3} \mathrm{H}$ as a nanoreactor for the one-pot, solvent-free synthesis of 1, 8-dioxo-9-aryl decahydroacridines," Journal of Heterocyclic Chemistry, vol. 49, pp. 111-115, 2012.

[51] A. A. Trabanco, G. Duvey, J. M. Cid et al., "New positive allosteric modulators of the metabotropic glutamate receptor 2 (mGluR2): identification and synthesis of N-propyl-8-chloro-6substituted isoquinolones," Bioorganic and Medicinal Chemistry Letters, vol. 21, no. 3, pp. 971-976, 2011.

[52] Y. Asano, S. Kitamura, T. Ohra et al., "Discovery, synthesis and biological evaluation of isoquinolones as novel and highly selective JNK inhibitors," Bioorganic and Medicinal Chemistry, vol. 16, no. 8, pp. 4699-4714, 2008.

[53] V. Krishnakumar, B. K. Mandal, K. M. Kumar, and F. N. Khan, "Flower-shaped $\mathrm{ZnO}$ nanoparticles as an efficient, heterogeneous and reusable catalyst in the synthesis of $\mathrm{N}$ arylhomophthalimides and benzannelated isoquinolinones," Research on Chemical Intermediates, vol. 38, pp. 1881-1892, 2012.

[54] B. Japelj, S. Rečnik, P. Čebašek, B. Stanovnik, and J. Svete, "Synthesis and antimycobacterial activity of alkyl 1-heteroaryl- $1 \mathrm{H}$ 1,2,3- triazole-4-carboxylates," Journal of Heterocyclic Chemistry, vol. 42, no. 6, pp. 1167-1173, 2005.

[55] A. K. Jordão, V. F. Ferreira, T. M. L. Souza et al., "Synthesis and anti-HSV-1 activity of new 1,2,3-triazole derivatives," Bioorganic and Medicinal Chemistry, vol. 19, no. 6, pp. 1860-1865, 2011.

[56] N. G. Aher, V. S. Pore, N. N. Mishra et al., "Synthesis and antifungal activity of 1,2,3-triazole containing fluconazole analogues," Bioorganic and Medicinal Chemistry Letters, vol. 19, no. 3, pp. 759-763, 2009.

[57] F. Alonso, Y. Moglie, G. Radivoy, and M. Yus, "Multicomponent click synthesis of potentially biologically active triazoles catalysed by copper nanoparticles on activated carbon in water," Heterocycles, vol. 84, pp. 1033-1044, 2012.

[58] J. Albadi, M. Keshavarz, F. Shirini, and M. Vafaie-nezhad, "Copper iodide nanoparticles on poly(4-vinyl pyridine): a new and efficient catalyst for multicomponent click synthesis of 1,4-disubstituted-1,2,3-triazoles in water," Catalysis Communications, vol. 27, pp. 17-20, 2012.

[59] H. Sharghi, A. Khoshnood, M. M. Doroodmand, and R. Khalifeh, "1,4-Dihydroxyanthraquinone-copper(II) nanoparticles immobilized on silica gel: a highly efficient, copper scavenger and recyclable heterogeneous nanocatalyst for a click approach to the three-component synthesis of 1,2,3-triazole derivatives in water," Journal of the Iranian Chemical Society, vol. 9, pp. 231-250, 2012.

[60] B. S. P. Anil Kumar, K. H. V. Reddy, B. Madhav, K. Ramesh, and Y. V. D. Nageswar, "Magnetically separable $\mathrm{CuFe}_{2} \mathrm{O}_{4}$ nano particles catalyzed multicomponent synthesis of 1,4-disubstituted 1,2,3-triazoles in tap water using 'click chemistry,', Tetrahedron Letters, vol. 53, pp. 4595-4599, 2012.

[61] B. Kaboudin, Y. Abedi, and T. Yokomatsu, "One-pot synthesis of 1,2,3-triazoles from boronic acids in water using $\mathrm{Cu}(\mathrm{II})-\beta$ cyclodextrin complex as a nanocatalyst," Organic Biomolecular Chemistry, vol. 10, pp. 4543-4548, 2012.

[62] V. Maddi, K. S. Raghu, and M. N. A. Rao, "Synthesis and antiinflammatory activity of 3-(benzylideneamino)coumarins in rodents," Journal of Pharmaceutical Sciences, vol. 81, no. 9, pp. 964-965, 1992.

[63] M. Roussaki, C. A. Kontogiorgis, D. Hadjipavlou-Litina, S. Hamilakis, and A. Detsi, "A novel synthesis of 3-aryl coumarins and evaluation of their antioxidant and lipoxygenase inhibitory activity," Bioorganic and Medicinal Chemistry Letters, vol. 20, no. 13, pp. 3889-3892, 2010.

[64] S. Sardari, Y. Mori, K. Horita, R. G. Micetich, S. Nishibe, and M. Daneshtalab, "Synthesis and antifungal activity of coumarins and angular furanocoumarins," Bioorganic and Medicinal Chemistry, vol. 7, no. 9, pp. 1933-1940, 1999.

[65] B. V. Kumar, H. S. B. Naik, D. Girija, and B. V. Kumar, "ZnO nanoparticle as catalyst for efficient green one-pot synthesis of coumarins through Knoevenagel condensation," Journal of Chemical Sciences, vol. 123, pp. 615-621, 2011.

[66] I. Manolov, C. Maichle-Moessmer, I. Nicolova, and N. Danchev, "Synthesis and anticoagulant activities of substituted 2,4-diketochromans, biscoumarins, and chromanocoumarins," Archiv der Pharmazie, vol. 339, no. 6, pp. 319-326, 2006.

[67] J. M. Khurana and K. Vij, "Nickel nanoparticles: a highly efficient catalyst for one pot synthesis of tetraketones and biscoumarins," Journal of Chemical Sciences, vol. 124, pp. 907912, 2012.

[68] Z. Bouaziz, J. Riondal, A. Mey, M. Berlion, J. Villard, and H. Fillion, "Synthesis of some naphthoxazine carbolactone derivatives with in vitro cytotoxic and antifungal activities," European Journal of Medicinal Chemistry, vol. 26, no. 4, pp. 469$472,1991$.

[69] A. Kumar, A. Saxena, M. Dewan, A. De, and S. Mozumdar, "Recyclable nanoparticulate copper mediated synthesis of naphthoxazinones in PEG-400: a green approach," Tetrahedron Letters, vol. 52, pp. 4835-4839, 2011.

[70] G. A. M. Nawwar, "Salicylamides containing amino acid or pyran moieties with molluscicidal activity," Archiv der Pharmazie, vol. 327, no. 4, pp. 201-205, 1994.

[71] A. Plant, A. Harder, N. Mencke, and H. Bertram, "Synthesis and anthelmintic activity of 7-hydroxy- 5-oxo-5H-thieno[3, 2-b]pyran-6-carboxanilides and -6-thiocarboxanilides," Pest Management Science, vol. 48, pp. 351-358, 1996.

[72] N. Babakhani and S. Keshipoor, " $\mathrm{TiO}_{2}$ and $\mathrm{TiO}_{2}$ nanoparticles as efficient and recoverable catalysts for the synthesis of pyran annulated heterocyclic systems," Research on Chemical Intermediates, 2012.

[73] H. Mehrabi and M. Kazemi-Mireki, "CuO nanoparticles: an efficient and recyclable nanocatalyst for the rapid and green synthesis of 3,4-dihydropyrano[c]chromenes," Chinese Chemical Letters, vol. 22, pp. 1419-1422, 2011.

[74] M. Khoobi, L. Ma'mani, F. Rezazadeh et al., "One-pot synthesis of $4 H$-benzo[b]pyrans and dihydropyrano[c]chromenes using inorganic-organic hybrid magnetic nanocatalyst in water," Journal of Molecular Catalysis A, vol. 359, pp. 74-80, 2012.

[75] S. Rostamizadeh, N. Shadjou, and M. Hasanzadeh, "Application of $\mathrm{MCM}-41-\mathrm{SO}_{3} \mathrm{H}$ as an advanced nanocatalyst for the solvent free synthesis of pyrano[3, 2-c]pyridine derivatives," Journal of the Chinese Chemical Society, vol. 59, pp. 866-871, 2012.

[76] H. Valizadeh and A. A. Azimi, " $\mathrm{ZnO} / \mathrm{MgO}$ containing $\mathrm{ZnO}$ nanoparticles as a highly effective heterogeneous base catalyst for the synthesis of $4 \mathrm{H}$-pyrans and coumarins in [bmim] $\mathrm{BF}_{4}$," Journal of the Iranian Chemical Society, vol. 8, no. 1, pp. 123-130, 2011.

[77] H. Nagabhushana, S. Sandeep Saundalkar, L. Muralidhar et al., " $\alpha-\mathrm{Fe}_{2} \mathrm{O}_{3}$ nanoparticles: an efficient, inexpensive catalyst for the one-pot preparation of 3,4-dihydropyrano $[c]$ chromenes," Chinese Chemical Letters, vol. 22, no. 2, pp. 143-146, 2011.

[78] M. Hosseini, R. Miri, M. Amini et al., "Synthesis, QSAR and calcium channel antagonist activity of new 1,4-dihydropyridine 
derivatives containing 1-methy 1-4,5-dichloroimidazolyl substituents," Archiv der Pharmazie, vol. 340, no. 10, pp. 549-556, 2007.

[79] I. Kruk, A. Kladna, K. Lichszteld et al., "Antioxidant activity of 4-flavonil-1,4-dihydropyridine derivatives," Biopolymers, vol. 62, no. 3, pp. 163-167, 2001.

[80] R. Murugan, K. Ramamoorthy, S. Sundarrajan, and S. Ramakrishna, "Magnesium oxide nanotubes: synthesis, characterization and application as efficient recyclable catalyst for pyrazolyl 1,4-dihydropyridine derivatives," Tetrahedron, vol. 68, pp. 71967201, 2012.

[81] C. Y. Fiakpui, O. A. Phillips, K. S. K. Murthy, and E. E. Knaus, "Synthesis and anticonvulsant activities of 5-(2-Chlorophenyl)7H-pyrido $[4,3-f][1,2,4]$ triazolo $[4,3-a][1,4]$ diazepines," Journal of Heterocyclic Chemistry, vol. 36, no. 2, pp. 377380, 1999.

[82] R. Ramajayam, R. Giridhar, M. R. Yadav et al., "Synthesis, antileukemic and antiplatelet activities of 2,3-diaryl-6,7dihydro-5H-1,4-diazepines," European Journal of Medicinal Chemistry, vol. 43, no. 9, pp. 2004-2010, 2008.

[83] A. Maleki, " $\mathrm{Fe}_{3} \mathrm{O}_{4} / \mathrm{SiO}_{2}$ nanoparticles: an efficient and magnetically recoverable nanocatalyst for the one-pot multicomponent synthesis of diazepines," Tetrahedron, vol. 68, pp. 7827-7833, 2012.

[84] E. Lukevics, L. Lgnatovich, I. Sleiksha et al., "Synthesis, structure and cytotoxic activity of 2-acetyl-5- trimethylsilylthiophene(furan) and their oximes," Applied Organometallic Chemistry, vol. 20, no. 7, pp. 454-458, 2006.

[85] A. Foroumadi, N. Mohammadhosseini, S. Emami et al., "Synthesis and antibacterial activity of new 7-piperazinylquinolones containing a functionalized 2-(furan-3-yl)ethyl moiety," Archiv der Pharmazie, vol. 340, no. 1, pp. 47-52, 2007.

[86] J. Safaei-Ghomi, M. A. Ghasemzadeh, and A. KakavandQalenoei, "CuI-nanoparticles-catalyzed one-pot synthesis of benzo[b]furans via three-component coupling of aldehydes, amines and alkyne," Journal of Saudi Chemical Society, 2012.

[87] N. Mulakayala, P. V. N. S. Murthy, D. Rambabu et al., "Catalysis by molecular iodine: a rapid synthesis of 1,8-dioxooctahydroxanthenes and their evaluation as potential anticancer agents," Bioorganic \& Medicinal Chemistry Letters, vol. 22, pp. 2186-2191, 2012.

[88] S. Rostamizadeh, A. M. Amani, G. H. Mahdavinia, G. Amiri, and H. Sepehrian, "Ultrasound promoted rapid and green synthesis of 1,8-dioxo-octahydroxanthenes derivatives using nanosized MCM-41- $\mathrm{SO}_{3} \mathrm{H}$ as a nanoreactor, nanocatalyst in aqueous media," Ultrasonics Sonochemistry, vol. 17, no. 2, pp. 306-309, 2010.

[89] I. Banti, S. Nencetti, E. Orlandini, A. Lapucci, M. C. Breschi, and S. Fogli, "Synthesis and in-vitro antitumour activity of new naphthyridine derivatives on human pancreatic cancer cells," Journal of Pharmacy and Pharmacology, vol. 61, no. 8, pp. 10571066, 2009.

[90] P. M. Sivakumar, G. Iyer, and M. Doble, "QSAR studies on substituted 3- or 4-phenyl-1,8-naphthyridine derivatives as antimicrobial agents," Medicinal Chemistry Research, vol. 21, pp. 788-795, 2012.

[91] S. Rostamizadeh, M. Azad, N. Shadjou, and M. Hasanzadeh, " $\left(\alpha-\mathrm{Fe}_{2} \mathrm{O}_{3}\right)-\mathrm{MCM}-41-\mathrm{SO}_{3} \mathrm{H}$ as a novel magnetic nanocatalyst for the synthesis of $\mathrm{N}$-aryl-2-amino-1, 6-naphthyridine derivatives," Catalysis Communications, vol. 25, pp. 83-91, 2012.

[92] A. Dandia, V. Parewa, and K. S. Rathore, "Synthesis and characterization of CdS and Mn doped CdS nanoparticles and their catalytic application for chemoselective synthesis of benzimidazoles and benzothiazoles in aqueous medium," Catalysis Communications, vol. 28, pp. 90-94, 2012.

[93] P. Gupta, S. Hameed, and R. Jain, "Ring-substituted imidazoles as a new class of anti-tuberculosis agents," European Journal of Medicinal Chemistry, vol. 39, no. 9, pp. 805-814, 2004.

[94] A. Khalafi-Nezhad, M. N. Soltani Rad, H. Mohabatkar, Z. Asrari, and B. Hemmateenejad, "Design, synthesis, antibacterial and QSAR studies of benzimidazole and imidazole chloroaryloxyalkyl derivatives," Bioorganic and Medicinal Chemistry, vol. 13, no. 6, pp. 1931-1938, 2005.

[95] H. Zang, Q. Su, Y. Mo, B. W. Cheng, and S. Jun, "Ionic liquid [EMIM]OAc under ultrasonic irradiation towards the first synthesis of trisubstituted imidazoles," Ultrasonics Sonochemistry, vol. 17, no. 5, pp. 749-751, 2010.

[96] M. V. Chary, N. C. Keerthysri, S. V. N. Vupallapati, N. Lingaiah, and S. Kantevari, "Tetrabutylammonium bromide (TBAB) in isopropanol: an efficient, novel, neutral and recyclable catalytic system for the synthesis of 2,4,5-trisubstituted imidazoles," Catalysis Communications, vol. 9, no. 10, pp. 2013-2017, 2008.

[97] S. Kantevari, S. V. N. Vuppalapati, D. O. Biradar, and L. Nagarapu, "Highly efficient, one-pot, solvent-free synthesis of tetrasubstituted imidazoles using $\mathrm{HClO}_{4}-\mathrm{SiO}_{2}$ as novel heterogeneous catalyst," Journal of Molecular Catalysis A, vol. 266, no. 1-2, pp. 109-113, 2007.

[98] B. F. Mirjalili, A. H. Bamoniri, and L. Zamani, "One-pot synthesis of 1,2,4,5-tetrasubstituted imidazoles promoted by nano- $\mathrm{TiCl}_{4} \cdot \mathrm{SiO}_{2}$," Scientia Iranica, Transactions $C$, vol. 19, pp. 565-568, 2012.

[99] G. M. Ziarani, A. Badiei, N. Lashgari, and Z. Farahani, "Efficient one-pot synthesis of 2,4,5-trisubstituted and 1,2,4,5tetrasubstituted imidazoles using $\mathrm{SBA}-\mathrm{Pr}-\mathrm{SO}_{3} \mathrm{H}$ as a green nano catalyst," Journal of Saudi Chemical Society, 2013.

[100] J. Safari, S. Gandomi-Ravandi, and Z. Akbari, "Sonochemical synthesis of 1,2,4,5-tetrasubstituted imidazoles using nanocrystalline $\mathrm{MgAl}_{2} \mathrm{O}_{4}$ as an effective catalyst," Journal of Advanced Research, 2012.

[101] A. Teimouri and A. N. Chermahini, "An efficient and onepot synthesis of 2,4,5-trisubstituted and 1,2,4,5-tetrasubstituted imidazoles catalyzed via solid acid nano-catalyst," Journal of Molecular Catalysis A, vol. 346, pp. 39-45, 2011.

[102] M. G. Hossein, A. A. Mohammad, and S. Hamid, "MCM-41$\mathrm{SO}_{3} \mathrm{H}$ as a highly efficient sulfonic acid nanoreactor for the rapid and green synthesis of some novel highly substituted imidazoles under solvent-free condition," Chinese Journal of Chemistry, vol. 30, pp. 703-708, 2012.

[103] B. Karami, K. Eskandari, and A. Ghasemi, "Facile and rapid synthesis of some novel polysubstituted imidazoles by employing magnetic $\mathrm{Fe}_{3} \mathrm{O}_{4}$ nanoparticles as a high efficient catalyst," Turkish Journal of Chemistry, vol. 36, pp. 601-614, 2012.

[104] S. J. Ahmadi, M. Hosseinpour, and S. Sadjadi, "Granulated copper oxide nanocatalyst: a mild and efficient reusable catalyst for the one-pot synthesis of 4-amino-5-pyrimidinecarbonitriles under aqueous conditions," Monatshefte fur Chemie, vol. 142, pp. 1163-1168, 2011.

[105] R. Hekmatshoar, G. N. Kenary, S. Sadjadi, and Y. S. Beheshtiha, "ZnO Nanoparticles: a mild and efficient reusable catalyst for the one-pot synthesis of 4-amino-5-pyrimidinecarbonitriles under aqueous conditions," Synthetic Communications, vol. 40, no. 13, pp. 2007-2013, 2010.

[106] M. M. Heravi, S. Sadjadi, S. Sadjadi, H. A. Oskooie, R. H. Shoar, and F. F. Bamoharram, "Supported preyssler nanoparticles in 
synthesis of 1,3-diaryl-5- spirohexahydropyrimidines," Journal of the Chinese Chemical Society, vol. 56, no. 2, pp. 246-250, 2009.

[107] B. W. J. Chen, L. L. Chng, J. Yang, Y. Wei, J. Yang, and J. Y. Ying, "Palladium-based nanocatalyst for one-pot synthesis of polysubstituted quinolines," Chem CatChem, vol. 5, pp. 277-283, 2013.

[108] S. J. Ahmadi, M. Hosseinpour, and S. Sadjadi, "Nanocrystalline copper(II) oxide-catalyzed one-pot synthesis of imidazo[1,2$a$ ]quinoline and quinolino[1,2- $a$ ]quinazoline derivatives via a three-component condensation," Synthetic Communications, vol. 41, no. 3, pp. 426-435, 2011.

[109] H. R. Prakash Naik, H. S. Bhojya Naik, T. R. Ravikumar Naik, T. Aravinda, and D. S. Lamani, " $\mathrm{TiO}_{2}$ nanopowder catalyzed microwave-induced one-pot synthesis of novel quinoline/benzo[ $h]$ quinoline3-carbonitrile under solvent free conditions," Phosphorus, Sulfur and Silicon and the Related Elements, vol. 184, no. 8, pp. 2109-2114, 2009.

[110] J. M. Nezhad, J. Akbari, A. Heydari, and B. Alirezapour, "CuO nanoparticles as an efficient and reusable catalyst for the onepot Friedlander quinoline synthesis," Bulletin of the Korean Chemical Society, vol. 32, pp. 3853-3854, 2011.

[111] M. So, Y. Liu, C. Ho, K. Lam, and C. Che, "Silica-supported gold nanoparticles catalyzed one-pot, tandem aerobic oxidative cyclization reaction for nitrogen-containing polyheterocyclic compounds," Chem CatChem, vol. 3, pp. 386-393, 2011.

[112] M. B. Gawande, A. Velhinho, I. D. Nogueira, C. A. A. Ghumman, O. M. N. D. Teodoro, and P. S. Branco, "A facile synthesis of cysteine-ferrite magnetic nanoparticles for application in multicomponent reactions-a sustainable protocol," The Royal Society of Chemistry, vol. 2, pp. 6144-6149, 2012.

[113] S. Abdolmohammadi, " $\mathrm{TiO}_{2}$ nanoparticles as an effective catalyst for the synthesis of hexahydro-2-quinolinecarboxylic acids derivatives," Chinese Chemical Letters, vol. 23, pp. 1003-1006, 2012.

[114] S. Sadjadi, R. Hekmatshoar, S. J. Ahmadi, M. Hosseinpour, and M. Outokesh, "On water: a practical and efficient synthesis of benzoheterocycle derivatives catalyzed by nanocrystalline copper(II) oxide," Synthetic Communications, vol. 40, no. 4, pp. 607-614, 2010.

[115] V. Polshettiwar and R. S. Varma, "Nano-organocatalyst: magnetically retrievable ferrite-anchored glutathione for microwave-assisted Paal-Knorr reaction, aza-Michael addition, and pyrazole synthesis," Tetrahedron, vol. 66, no. 5, pp. 1091-1097, 2010.

[116] H. Li, Z. Zhu, F. Zhang et al., "Palladium nanoparticles confined in the cages of MIL-101: an efficient catalyst for the one-pot indole synthesis in water," ACS Catalysis, vol. 1, pp. 1604-1612, 2011.

[117] R. Parella, Naveen, and S. A. Babu, "Magnetic nano $\mathrm{Fe}_{3} \mathrm{O}_{4}$ and $\mathrm{CuFe}_{2} \mathrm{O}_{4}$ as heterogeneous catalysts: a green method for the stereo- and regioselective reactions of epoxides with indoles/pyrroles," Catalysis Communications, vol. 29, pp. 118121, 2012.

[118] S. M. Roopan and F. R. N. Khan, "ZnO nanorods catalyzed $\mathrm{N}$-alkylation of piperidin-4-one, $4(3 \mathrm{H})$-pyrimidone, and ethyl 6-chloro-1,2-dihydro-2-oxo-4-phenylquinoline-3-carboxylate," Chemical Papers, vol. 64, no. 5, pp. 678-682, 2010.

[119] S. M. Roopan, M. Gund, F. N. Khan, R. Kumar, J. S. Jin, and A. S. Kumar, "Regioselective O-alkylation: synthesis of 1-2[(2chloroquinolin-3-yl)methoxy]-6-chloro-4phenylquinolin3-ylethanones," Research on Chemical Intermediates, vol. 38, pp. 1111-1118, 2012.
[120] S. M. Roopan, F. R. N. Khan, and B. K. Mandal, "Fe nano particles mediated $\mathrm{C}-\mathrm{N}$ bond-forming reaction: regioselective synthesis of 3-[(2-chloroquinolin-3-yl)methyl]pyrimidin4(3H)ones," Tetrahedron Letters, vol. 51, no. 17, pp. 2309-2311, 2010 . 

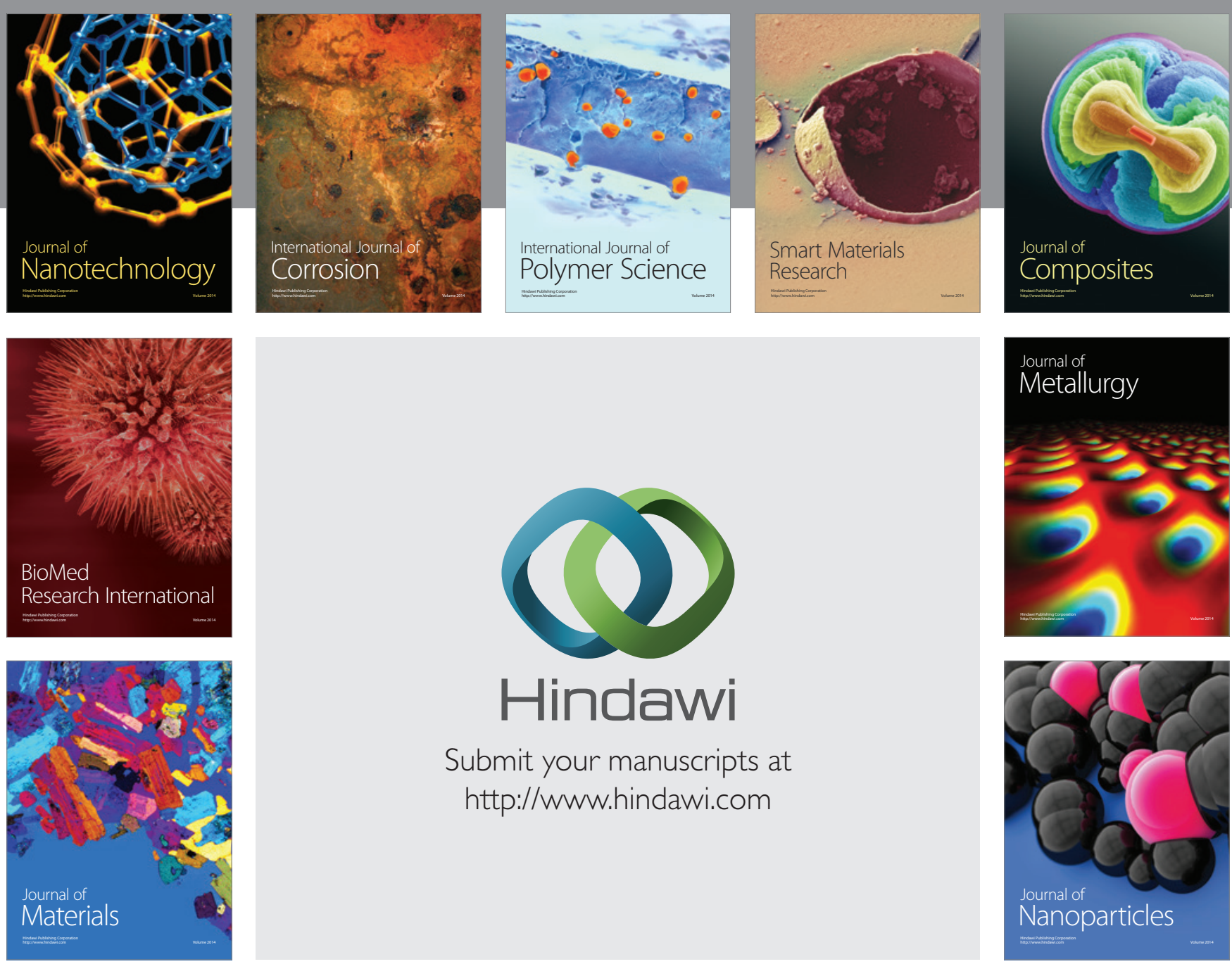

Submit your manuscripts at http://www.hindawi.com
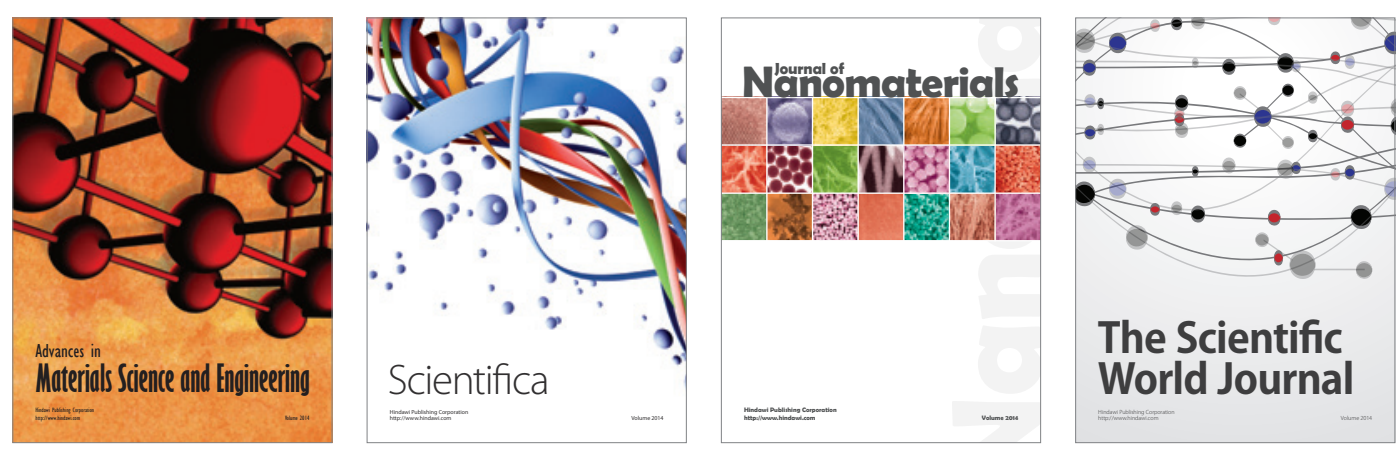

\section{The Scientific World Journal}
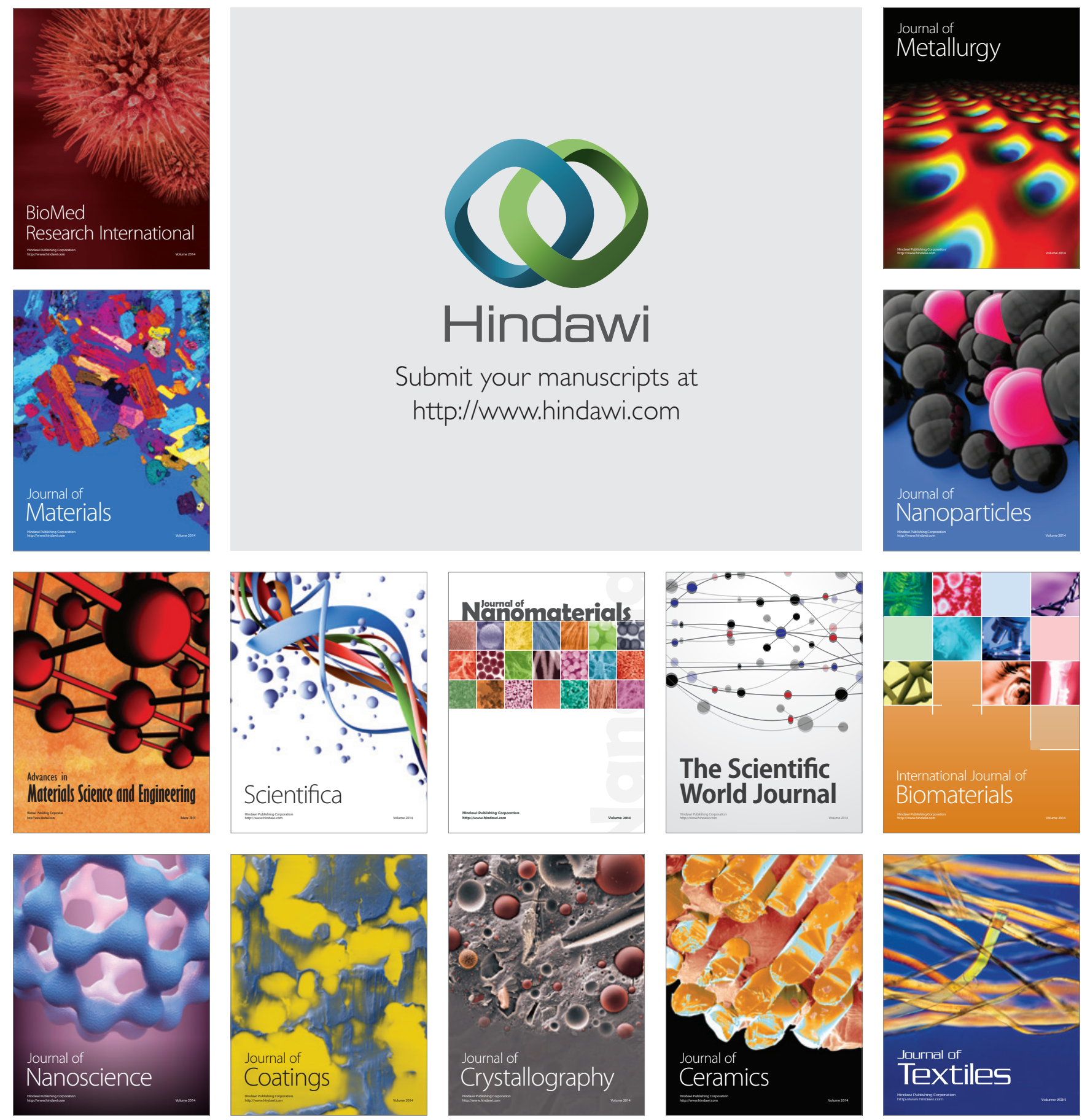